\title{
THE ENVIRONMENTAL KUZNETS CURVE IN THE CEE COUNTRIES - THE THRESHOLD COINTEGRATION APPROACH
}

The aim of the paper is the investigation of the long-run relationship between carbon dioxide emissions and economic growth in the Central and East European countries with special emphasis on a decoupling of carbon emissions and economic growth. The implementation of threshold cointegration with asymmetric adjustment enables detecting the changes in the non-linear pollutant-income relationship in the long-run, and in consequence allows to identify the non-linear causal link among $\mathrm{CO}_{2}$ emissions, GDP and energy consumption in a more comprehensive way and formulate more reliable recommendations for energy policy. The main contribution of the paper lies in testing the standard EKC hypothesis and its extended version by adding energy consumption and time trend for the CEE countries in order to test the robustness of the results. We also concentrate on the identification of the short-run and long-run causal relationship between per capita $\mathrm{CO}_{2}$ emissions and per capita income using threshold error correction models (T-ECM) and momentum threshold error correction model (M-TECM). There is significant evidence that the inverted U-shape (EKC) holds between per capita $\mathrm{CO}_{2}$ and GDP per capita for the Czech Republic, Slovakia and Romania meaning that economic growth decouples from $\mathrm{CO}_{2}$ emissions. This finding can be interpreted in terms of effective environmental policy directed into the reduction of $\mathrm{CO}_{2}$ emissions in these countries. We also find that temporary disequilibrium from the long-run EKC is corrected in an asymmetric fashion for Romania, Slovenia, Estonia in the framework of the standard EKC model, and additionally for the Czech Republic and Bulgaria (besides Slovenia and Estonia) based on the extended specification of EKC model.

Keywords: Environmental Kuznets curve, decoupling economic growth from carbon dioxide emissions, energy consumption, threshold cointegration, nonlinear error correction

DOI: $10.15611 /$ aoe.2017.2.13

\section{INTRODUCTION}

The evidence on the existence of the pollutant-income relationship has been widely presented from the theoretical point of view with the detailed description of the key drivers that may strengthen or weaken this linkage in Grossman and Krueger (1993), Shafik and Bandyopadhyay (1992), Panayotou (1993), Wyckoff and Roop (1994), Panayotou (1997), Suri and Chapman

\footnotetext{
${ }^{*}$ Nicolaus Copernicus University.

${ }^{* *}$ Czestochowa University of Technology.
} 
(1998), Heil and Selden (1999), Friedl and Getzner (2003), Dinda (2004), Stern (2004), Carson (2010), He and Richard (2010), Kijima et al. (2010), Pasten and Figueroa (2012). The fundamental issue whether economic development may only cause environmental degradation or whether it may also improve the environment has not been clearly resolved. Some environmental economists think that economic growth leads to an increase in environmental pollution which means that the pollutant-income relationship is monotonically increasing (Shafik, 1994; Cole et al., 1997; Roca, 2003; Wagner, 2008). Yet according to other researchers' opinions, the pollution level increases as a country develops, until this development reaches a turning point and after that the rising incomes are accompanied by decreasing environmental degradation (Grossman and Krueger, 1993; Shafik and Bandyopadhyay, 1992; Panayotou, 1993; Holtz-Eakin and Selden, 1995; Agras and Chapman, 1999; Apergis and Payne, 2009; Iwata et al., 2010; Esteve and Tamarit, 2012; Fosten et al., 2012). This phenomenon is described by the inverted U-shaped relationship which is known as the Environmental Kuznets Curve (EKC).

It is worth stressing that several determinants are responsible for the $\mathrm{EKC}$ validity, including structural changes in the economy (from a clean agrarian economy to a polluting industrial economy to a clean service economy) ${ }^{1}$, technological progress as a result of the higher level of spending on R\&D in wealthier countries ${ }^{2}$, the scale effect (the increasing output is accompanied by the increase in natural resources use and pollutant emissions). Moreover, international trade connected with changes in international specialization (Pollution Haven Hypothesis; Cole, 2004), as well as technology diffusion (Martin and Wheeler, 1992) become more and more important factors leading to the appearance of the inverted U-shaped relationship between economic growth and environmental degradation. In the theoretical and empirical studies devoted to the EKC hypothesis one can also point to the significance of the following issues: implementation of environmental regulation (in both forms: command-and-control policy and market-oriented regulations, Dasgupta et al., 2002), the growing demand for environmental quality along with the enrichment of society (Dinda, 2004), substitution of more environmentally damaging inputs for less damaging resources in the production process according to the stage of economic development (Stern, 2004), in particular the increase of renewable energy share in total primary

\footnotetext{
${ }^{1}$ It is also known as the composition effect (Grossman and Krueger, 1991).

${ }^{2}$ This is a technique effect due to public R\&D funding for environmental protection (Komen et al., 1997).
} 
energy consumption. The above-mentioned factors will work if they are accompanied by an active government policy directed at the greenhouse gas emissions reduction and the protection of the environment. Therefore a model describing pollutant-income relationship may be a useful tool designed to evaluate the environmental policy effectiveness in individual countries.

The criticism of empirical studies over the EKC hypothesis validity involves the following aspects: the characteristics of the pollutant in question, various econometric methods, the assumption about a common developmental pattern in all countries, lack of a reliable and comparable data set for the EKC variables, and omitted variables bias (Lieb, 2003; Dinda, 2004; Kaika and Zervas, 2013). Moreover, due to data limitations, researchers often used cross-sectional or panel data techniques for testing the EKC hypothesis (Richmond and Kaufmann, 2006; Apergis and Payne, 2009, 2010; Narayan and Narayan, 2010; Jaunky, 2011; Antczak and Suchecka, 2011; Wang, 2012; Ozcan, 2013; Antczak, 2013; Farhani et al., 2013; Papież, 2013; Baek, 2015). Taking into consideration the heterogeneity of conditions observed in social, economic and political factors, the economic development trajectory for an individual country may not be the same as a pattern of a group of countries. Thus an approach with standard panel data techniques which assumes that the existence of one pattern of the EKC relationship for both developed and developing countries can lead to a biased interpretation of empirical results and could not offer much guidance on policy implications for each country (Baek and Kim, 2011; Hill and Magnani, 2002; Dinda, 2004; Stern, 2004, Fosten et al., 2012). The above conclusions show the necessity to carry out studies that capture the specific character of the long-term relationship between economic growth and environmental degradation individually for each country (Ang, 2007; Soytas et al., 2007; Soytas and Sari, 2009; Jail and Mahmud, 2009; Acaravci and Ozturk, 2010; Fodha and Zaghdoud, 2010; Esteve and Tamarit, 2012; Fosten et al., 201); Saboori et al., 2012; Shahbaz et al., 2013; Piłatowska et al., 2014; Piłatowska et al., 2015; Tang and Tan, 2015; Baek, 2015). These studies also detected a wide variety of findings as a consequence of the diversity of pollutant-income model specifications, various sample ranges and different data sources (Dinda, 2004; Lieb, 2003; Carson, 2010). The common feature of these studies was the linear approach and symmetric cointegration which may be a possible reason for the ambiguous results. It has been suggested more recently (Balke and Fomby, 1997; Enders and Granger, 1998; Enders and Siklos, 2001) that the adjustment of deviations toward the long-term equilibrium need not be symmetric and reverting each 
period. To our knowledge there are very few studies that use threshold cointegration techniques for testing the EKC hypothesis (Fosten et al., 2012; Esteve and Tamarit, 2012).

Taking the above into consideration, the aim of our study is the investigation of the long-term relationship between carbon dioxide emissions and economic growth in the Central and East European countries (CEE) with a special emphasis on the decoupling between economic growth and carbon emissions. The implementation of threshold cointegration with asymmetric adjustment enables detecting the changes in the non-linear pollutant-income relationship in the long-term, and as a consequence allows to identify the non-linear causal link among $\mathrm{CO}_{2}$ emissions, GDP and energy consumption in a more comprehensive way, and formulate more reliable recommendations for energy policy.

The main contribution of the paper lies in testing the standard EKC hypothesis and its extended version including energy consumption for the CEE countries using threshold autoregressive (TAR) and momentum threshold autoregressive (MTAR) cointegration of Enders and Siklos (2001). We will also concentrate on the identification of the short and long-term causal relationship between per capita $\mathrm{CO}_{2}$ emissions and per capita income using threshold error correction models (T-ECM) and the momentum threshold error correction model (M-TECM). The next contribution of this paper is that it employs a relatively large number of observations obtained by the disaggregation of annual time-series data to quarterly data, i.e. from 1995:Q1 to 2012:Q4, with enough period span to capture such important events as: the agreement of the Kyoto Protocol (1997), the CEE countries' accession to the European Union (2004 or 2007), the subprime financial crisis (2007) and the European debt crisis (2009).

It is worth underlining that the fall of the Iron Curtain and the socioeconomic transformations in the CEE countries which started at the turn of 1989-1990 caused, among others, a change in the ownership structure of each economy (the development of private enterprises and the privatization of public property), the elimination of political barriers in these countries, visa-free travel for the citizens of most countries, and the use of EU funds for the elimination of regional development disparities. All of these factors contributed to rapid economic growth in these countries. On the other hand, the dependence on Russian energy in some of the analyzed countries remained unchanged, especially in the case of natural gas and oil. This import dependence is a severe problem and it may be reduced by economizing on energy use, the price and tax systems leading to energy savings and the 
promotion of renewable energy resources. All these activities may contribute to the improvement of energy supply security and reductions in the energy intensity in the CEE countries.

During this period many energy and climate policies were implemented in the analyzed countries. To improve energy efficiency and to reduce the human effects on climate change (especially to reduce $\mathrm{CO}_{2}$ emissions) different measures have been proposed such as the EU emission trading scheme, the white certificates, financial incentives, voluntary agreements and legislative measures. Therefore investigation as to economic growth decoupled from emission levels can be helpful to measure the implementation status of environmental policy (Annabelle, 2007) and to provide new information for policy-making in the CEE countries. To the best of our knowledge there is no such study that uses the threshold cointegration approach to identify possible non-linearity in the $\mathrm{CO}_{2}-\mathrm{GDP}$ relationship for the CEE countries studied in this paper.

The remainder of this paper is organized as follows. Section 2 presents the environmental Kuznets curve and describes the methodology employed in the analysis. Section 3 describes the data and Section 4 reports the empirical results. The last section concludes.

\section{THE METHODOLOGY}

In order to explore the impact of economic development on environmental quality we focus on the estimation and verification of the Environmental Kuznets Curve for the Central and East European countries. Typically, the level of the environmental degradation indicator is modelled as the quadratic function of the level of income, according to the following equation (Agras and Chapman, 1999):

$$
C O_{t}=\alpha_{0}+\alpha_{1} G D P_{t}+\alpha_{2} G D P_{t}^{2}+\mu_{t},
$$

where $C O_{t}$-emissions of some pollutant (per capita), $G D P_{t}$ - real income (per capita), both variables are in logarithms ${ }^{3}, \alpha_{0}, \alpha_{1}, \alpha_{2}$ - estimated parameters, $\mu_{t}$ error term that may be serially correlated. It is worth underlining that $\alpha_{1}$ and $\alpha_{2}$ parameters are interpreted as income elasticity of demand for environmental quality (Lieb, 2004).

\footnotetext{
${ }^{3}$ All the variables are in natural logarithms in order to stabilize the variance and obtain the growth rate of the relevant variables by computing their first differences.
} 
In cases when estimates of $\alpha_{1}$ and $\alpha_{2}$ parameters are statistically significant we can make conclusions about the shape of environmental pollution and economic growth linkage. One ought to examine the position and the shape of the non-linear fitted curve, as well as the value of the corresponding turning point in order to identify the pollution-income relationship. The turning point value is derived from equation (1) (Stern, 2004):

$$
G D P_{T P}=\exp \left(-\frac{\alpha_{1}}{2 \alpha_{2}}\right), \alpha_{2} \neq 0 .
$$

This turning point exists in the following two cases: if $\alpha_{2}<0$ and $\alpha_{1}>0$, then the maximum value of carbon dioxide emissions is observed at the GDP turning point; if $\alpha_{2}>0$ and $\alpha_{1}<0$, then the minimum value of $\mathrm{CO}_{2}$ emissions is reached at the GDP turning point. In the first case, the Environmental Kuznets Curve exists and the inverted U-shape relationship between pollutant emissions and income is observed. According to this model, environmental degradation increases with per capita income and then declines with per capita income after arriving at a threshold. In the second case, a U-shape curve reflects the situation when first, environmental pollution is falling with per capita income and then, after reaching some threshold level of income, the pollution is rising with a higher income level (List and Gallet, 1999; Kaufmann et al., 1998; Dinda et al., 2000; Khanna, 2002).

However, this case should be rather considered as a temporary state because it is expected that the environmental policy rules together with the EU climate and energy obligations implemented in the individual country will lead to the abatement of greenhouse gases emissions. In such a situation, the second branch of this U-shape curve will flatten out in such a way that the second turning point of income will appear in the future and the pollution-income relationship will be transformed into the inverted $\mathrm{N}$-shape curve. The occurrence of the second turning point means that the environmental degradation will decline with per capita income after reaching this threshold value of income. The inverted N-shape curve for a cubic polynomial of income factor is considered for example by Gangadharan and Valenzuela (2001), Harbaugh et. al. (2002), Fodha and Zaghdoud (2010), Fosten et al. (2012):

$$
C O_{t}=\alpha_{0}+\alpha_{1} G D P_{t}+\alpha_{2} G D P_{t}^{2}+\alpha_{3} G D P_{t}^{3}+\mu_{t},
$$

where: $\alpha_{3}<0, \alpha_{2}>0, \alpha_{1}<0$. 
Since energy consumption by fuel type is at the essence of the environmental problem as well as being a crucial determinant controlling economic development, we incorporate this exogenous variable into the standard EKC model. Furthermore, deterministic time trend may be also included in equation (1) to capture the effect of technological progress on the pollution emission level. Therefore, to study the robustness of the pollution-income relationship identification results, we consider the following extended version of the EKC model:

$$
C O_{t}=\alpha_{0}+\alpha_{1} G D P_{t}+\alpha_{2} G D P_{t}^{2}+\gamma E_{t}+\beta t+\mu_{t},
$$

where: $E_{t}$ - energy consumption (per capita), $\gamma$ - estimated parameter (energy consumption elasticity of demand for environmental quality), $t$ - linear deterministic trend, $\beta$ - estimated parameter (growth rate of environmental pollution).

At the beginning we incorporate the nonlinear cointegration approach in order to test the EKC hypothesis both in the standard and extended version. As Balke and Fomby (1997) explained, the system in which the variables are cointegrated can discontinuously respond to deviations from the long-term equilibrium. This is because economic agents have to bear relatively high adjustment costs, which may be compensated for by the benefits of adjustments only if the deviations from the equilibrium exceed a given threshold value. If the benefits of adjustment exceed the costs, then the economic agents are encouraged to take up activities to move the system back to the long-term equilibrium, so the adjustment process is discrete. In that case an error correction model with asymmetric adjustment seems to be a promising tool to describe the nonlinear behaviour of the EKC (Esteve and Tamarit, 2012). The concept of threshold cointegration was proposed by Enders and Siklos (2001) who showed that a standard cointegration framework assuming symmetric adjustment toward equilibrium is misspecified if the adjustment process is asymmetric. They developed the nonlinear cointegration taking into account this asymmetric behaviour and allowing for different adjustment speeds in two regimes based on two modifications to the standard Dickey-Fuller regression in order to test for asymmetric cointegration, i.e. Threshold Autoregressive (TAR) or Momentum Threshold Autoregressive (MTAR) (Enders and Siklos, 2001). According to the two-step residualbased cointegration tests, the long-term relationship (1) or (4) is estimated by means of the Ordinary Least Squares (OLS) method (the first stage is common for both linear and nonlinear approach), and then (the second stage) 
on the basis of its residuals one of the following threshold regression specifications is determined (Enders and Siklos, 2001):

$$
\Delta \hat{\mu}_{t}=I_{t} \rho_{1} \hat{\mu}_{t-1}+\left(1-I_{t}\right) \rho_{2} \hat{\mu}_{t-1}+\sum_{i=1}^{r} \theta_{i} \Delta \hat{\mu}_{t-i}+\varepsilon_{t},
$$

where $\hat{\mu}_{t}$ is the disturbance term from equation (1) or (4), $\rho_{1}$ and $\rho_{2}$ are the speed of adjustment parameters, $\rho_{1}<0, \rho_{2}<0$ and $\left(1+\rho_{1}\right)\left(1+\rho_{2}\right)<1$ ${ }^{4}, \theta_{i}(i=1,2, \ldots, r)$ are estimated parameters, $\varepsilon_{t}$ is a white noise disturbance, $I_{t}$ is the Heaviside indicator function whose values are dependent on:

- the lagged residuals $\hat{\mu}_{t}$ (TAR specification)

$$
I_{t}= \begin{cases}1 & \text { if } \hat{\mu}_{t-1} \geq \tau \\ 0 & \text { if } \hat{\mu}_{t-1}<\tau\end{cases}
$$

- the lagged changes in residuals $\hat{\mu}_{t}$ (MTAR specification)

$$
I_{t}= \begin{cases}1 & \text { if } \Delta \hat{\mu}_{t-1} \geq \tau \\ 0 & \text { if } \Delta \hat{\mu}_{t-1}<\tau\end{cases}
$$

where $\tau$ is a threshold value, consistently estimated by Chan's (1993) method ${ }^{5}$. In equations (5) the Akaike Information Criterion (AIC) or the Schwarz Bayesian Criterion (SBC) may be used to determine the appropriate lag length.

It is worth stressing that the TAR specification allows to distinguish whether the deviations from the long-term equilibrium are above or below the threshold and how quickly they are corrected, while the MTAR model matters only the direction in which deviations are moving. In other words, MTAR specification enables to display whether changes of deviations are increasing or decreasing and how quickly they are corrected (Fosten et al., 2012). There is no prescribed rule of the choice between TAR and MTAR models, but it is recommended to select the best asymmetric adjustment mechanism using the AIC or SBC information criteria (Enders and Chumrusphonlert, 2004).

\footnotetext{
${ }^{4}$ According to Petruccelli and Woolford (1984) these are the necessary and sufficient conditions for the stationarity of residuals $\left\{\mu_{t}\right\}$ from the EKC model for any threshold value $\tau$ (Enders and Siklos, 2001).

${ }^{5}$ Chan's method to find the consistent estimate of the threshold value arranges the values $\mu_{t-1}$ or $\Delta \mu_{t-1}$ in ascending order, excludes the smallest and largest 15 percent, and the parameter that yields the smallest sum of squared residuals over the remaining 70 percent is the consistent estimate of the threshold.
} 
Once threshold value $\tau$ is obtained and the TAR or MTAR models are estimated ((1) or (4) and (5)-(7)), then testing for threshold cointegration is performed in two steps. Firstly, the null hypothesis of no cointegration $H_{0}: \rho_{1}=\rho_{2}=0$ is tested by the $\Phi_{\mu}$ statistic estimation, which is the $F$-type statistic of non-standard distribution, so it must be compared with appropriate critical values tabulated by Enders and Siklos (2001) and later modified by Wane et al. (2004). Secondly, when it is rejected, then the null hypothesis of symmetric adjustment, $\mathrm{H}_{0}: \rho_{1}=\rho_{2}$, is verified using the standard $F$ statistic. Rejecting both the null hypotheses of $\rho_{1}=\rho_{2}=0$ and $\rho_{1}=\rho_{2}$ implies the existence of threshold cointegration with asymmetric adjustment. For instance, if the null of symmetric adjustment is rejected and $\left|\rho_{1}\right|<\left|\rho_{2}\right|$, then it implies that deviations above the threshold tend to persist, and deviations below the threshold tend to revert quickly back toward the long-term EKC equilibrium. This methodology of testing for asymmetric and nonlinear cointegration, which is based on the threshold autoregressive or momentum threshold autoregressive model, constitutes a generalization (Fosten et al., 2012) of the two-step cointegration procedure of Engle and Granger (1987).

Given the threshold cointegration is found, the next step proceeds with the Granger-causality test using the advanced threshold error correction model (TECM) or the momentum-threshold error correction model (M-TECM) ( Enders and Granger, 1998; Enders and Siklos, 2001). The threshold ECM is expressed as follows:

$$
\begin{gathered}
\Delta Y_{j t}=\beta_{0}+\sum_{i=1}^{q_{1}} \delta_{i} \Delta C O_{t-i}+\sum_{j=1}^{q_{2}} \theta_{j} \Delta G D P_{t-j} \\
+\sum_{\kappa=1}^{q_{3}} \phi_{\kappa} \Delta G D P_{t-\kappa}^{2}+\gamma_{1} E C T_{t-1}^{+}+\gamma_{2} E C T_{t-1}^{-}+v_{t},
\end{gathered}
$$

or when additional variable $E_{t}$ is included:

$$
\begin{aligned}
& \Delta Y_{j t}=\beta_{0}+\sum_{i=1}^{q_{1}} \delta_{i} \Delta C O_{t-i}+\sum_{j=1}^{q_{2}} \theta_{j} \Delta G D P_{t-j}+\sum_{\kappa=1}^{q_{3}} \phi_{\kappa} \Delta G D P_{t-\kappa}^{2} \\
& +\sum_{t=1}^{q_{4}} \delta_{t} \Delta E_{t-l}+\gamma_{1} E C T_{t-1}^{+}+\gamma_{2} E C T_{t-1}^{-}+v_{t},
\end{aligned}
$$

where $\Delta Y_{j t}=\left(\Delta C O_{t}, \Delta G D P_{t}\right), \quad \beta_{0}, \quad \delta_{i}\left(i=1,2, \ldots, q_{1}\right), \quad \theta_{j}\left(j=1,2, \ldots, q_{2}\right)$, $\phi_{\kappa}\left(\kappa=1,2, \ldots, q_{3}\right), \alpha_{t}\left(t=1,2, \ldots, q_{4}\right)$ are estimated parameters ${ }^{6}, E C T_{t-1}^{+}=I_{t} \hat{\mu}_{t-1}$

\footnotetext{
${ }^{6}$ The appropriate lag selection is based on AIC or SBC information criterions.
} 
and $E C T_{t-1}^{-}=\left(1-I_{t}\right) \hat{\mu}_{t-1}$ are regime-dependent error correction terms, $I_{t}$ is the Heaviside indicator function determined by (6) or (7), $\hat{\mu}_{t-1}$ is obtained from the estimated long-term relationship (1) or (4), $\gamma_{1}$ and $\gamma_{2}$ are estimated parameters showing how quickly variables converge to the equilibrium in each regime, $\gamma_{1}<0, \gamma_{2}<0$, and $v_{t}$ is a white noise disturbance.

Based on equations (8) and (9), the Granger-causality tests are employed in the extended version which allows for different causal relationship patterns between pollutant emissions, income and energy consumption in particular regimes. We explore the causal relationships in three ways (Yau and Nieh, 2009):

- the short-term Granger causality (or weak causality) is identified using the Wald and F-tests for the joint significance of chosen parameters set associated with the first differenced explanatory variables $\left(H_{0}: \delta_{i}=0\right.$, $\left.H_{0}: \theta_{j}=0, H_{0}: \varphi_{\kappa}=0, H_{0}: \alpha_{\iota}=0\right)$,

- the long-term Granger causality is determined by the t-test for significance of adjustment parameters (error-correction term parameters) $\gamma_{1}$ and $\gamma_{2}\left(H_{0}: \gamma_{r}=0, r=1,2\right)$;

- the joint effect of these two sources of causation (short and long-term) is examined based on the Wald-F-test for the significance of the regimedependent error-correction parameter and the parameters for the chosen explanatory variable $\left(H_{0}: \delta_{i}=\gamma_{r}=0, H_{0}: \theta_{j}=\gamma_{r}=0, H_{0}: \varphi_{\kappa}=\gamma_{r}=0\right.$, $\left.H_{0}: \alpha_{t}=\gamma_{r}=0\right)$. The joint test indicates which variables bear the burden of short-term adjustment to re-establish long-term equilibrium, given a shock to the system (Asafu-Adjaye, 2000; Mehrara et al., 2012). This is referred to as the strong Granger causality test.

The methodology described above enables the identification of not only the sources of causation but also the non-linear adjustment in the relationship between carbon dioxide emissions and economic development with the asymmetric framework.

\section{DATA DESCRIPTION}

To carry out our analysis we employ time-series data on: carbon dioxide emissions $\left(\mathrm{CO}_{t}\right)$ (measured in metric tons per capita), real gross domestic product per capita $\left(G D P_{t}\right)$ (measured in constant 2005 U.S. dollars), gross inland energy consumption $\left(E_{t}\right)$ (measured in kilo of oil equivalent per 
capita), for 10 Central and East European countries (CEECs). The selected CEE countries included in the sample are Bulgaria, the Czech Republic, Estonia, Hungary, Lithuania, Latvia, Poland, Romania, the Slovak Republic and Slovenia ${ }^{7}$. Carbon dioxide emissions and energy consumption data are obtained from the Eurostat database, while real gross domestic product data are collected from the World Bank Development Indicators (WDI) online database. Our sample covers the period of 1995-2012 due to data availability for all the CEE countries. It is worth stressing that limited access to reliable data sets (especially GDP time series) was caused by the collapse of the Communist Bloc and the economic transformation which started at the turn of 1989-1990. Since all variables are only accessible at annual frequency, we interpolated annual data to quarterly frequency by employing the Denton-Cholette method (Sax and Steiner, 2013) in the R software ${ }^{8}$. Finally, the sample period is from 1995:Q1 to 2012:Q4.

Before investigating the pollutant-economic growth relationship across the CEE countries it is worth considering the structure of energy consumption which differs among the countries (see Table 1).

Table 1

Gross inland energy consumption in 2013 (\% of total, based on tonnes of oil equivalent)

\begin{tabular}{l|c|c|c|c|c|c}
\hline \multicolumn{1}{c|}{ Country } & $\begin{array}{c}\text { Solid } \\
\text { fuels }\end{array}$ & $\begin{array}{c}\text { Petroleum } \\
\text { products }\end{array}$ & Gases & Nuclear & Renewable & $\begin{array}{c}\text { Waste (non- } \\
\text { renewable) }\end{array}$ \\
\hline Bulgaria & 35.3 & 20.8 & 14.2 & 21.9 & 10.8 & 0.0 \\
\hline Czech Rep & 38.8 & 20.3 & 16.5 & 18.9 & 8.5 & 0.5 \\
\hline Estonia & 66.0 & 16.1 & 8.3 & 0.0 & 12.7 & 1.6 \\
\hline Hungary & 1.6 & 31.5 & 27.0 & 0.0 & 36.1 & 1.2 \\
\hline Latvia & 4.2 & 36.2 & 32.4 & 0.0 & 18.1 & 0.2 \\
\hline Lithuania & 10.3 & 25.3 & 33.9 & 17.5 & 8.3 & 0.2 \\
\hline Poland & 54.0 & 23.3 & 14.0 & 0.0 & 8.7 & 0.5 \\
\hline Romania & 17.8 & 25.9 & 30.3 & 9.3 & 17.2 & 0.1 \\
\hline Slovakia & 19.7 & 34.9 & 10.1 & 19.9 & 16.5 & 0.5 \\
\hline Slovenia & 20.0 & 19.4 & 27.9 & 23.8 & 8.2 & 0.7 \\
\hline
\end{tabular}

Source: based on Eurostat data.

\footnotetext{
${ }^{7}$ We selected this group of CEE countries based on the World Bank statement that "the transition is over for the 10 countries that joined the EU in 2004 and 2007"; see: Unleashing Prosperity: Productivity Growth in Eastern Europe and the Former Soviet Union, World Bank, Washington, 2008.

${ }^{8}$ The Denton-Cholette method allows for temporal disaggregation without high frequency indicator series, i.e. as a special case, a constant can be embodied as an indicator. Based on this we performed the time series disaggregation in the paper.
} 
For most of the Central and Eastern European countries the energy consumption was spread across a range of different energy sources, the most important of which in terms of size of its contribution were still solid fuels. It should be noted that more than half of the total energy consumption came from imported sources. The significance of solid fuel energy was particularly high in Estonia and Poland where it accounted for $66 \%$ and $54 \%$ of the total energy consumption, respectively. The share of crude oil and gas was also high across the CEE countries, from $16 \%$ to $36 \%$ for crude oil and from $8 \%$ to $34 \%$ for gas. The share of renewables in total energy consumption differed across countries: the smallest share of about $8 \%$ was in the Czech Republic, Poland, Lithuania and Slovenia and the largest - in Hungary (36.1\%). Nuclear energy was important in Bulgaria, the Czech Republic, Lithuania, Slovakia and Slovenia where it accounted for about $20 \%$ of total energy consumption, while in Romania this share was $9 \%$, with no contribution from nuclear energy in four of the CEE countries. This variety of energy sources reflects the availability of different fossil fuel deposits and the potential for water, solar and wind power among the CEE countries and on the other hand, the different policy approach towards nuclear fuels and renewables. Simultaneously, these different energy sources imply extremely different $\mathrm{CO}_{2}$ emissions, e.g. the carbon emission factor for solid fossil fuels is much higher than for natural gas, and equal to nil for wind, water and solar energy.

\section{EMPIRICAL RESULTS}

\subsection{Standard specification of the EKC model and threshold cointegration analysis}

The empirical study consists of two parts. In the first one we look at the long-term relationship between $\mathrm{CO}_{2}$ emissions and economic growth (EKC) in given CEE countries. We start with testing the threshold cointegration, and when it is not found, we continue with testing the linear cointegration. In each case the shape of the long-term relationship is checked, i.e. whether it is an inverted U-shape (EKC) or a U-shape, depending on a sign of $\alpha_{2}$ parameter estimates. In other words we investigate whether the EKC hypothesis is valid or not. This part of empirical analysis is supplemented by identifying the existence of Granger-causal relationships between $\mathrm{CO}_{2}$ emissions and economic growth both in short and long-term. In the second part we employ the same cointegration methodology and Granger causality 
tests to the EKC model extended by adding time trend and/or energy consumption to control the impact of technological changes and changes in energy consumption on the nature of pollutant-economic growth relationship.

The preliminary stage of cointegration analysis consists in determining the order of integration for all the EKC variables. We employ the Augmented Dickey-Fuller Generalized Least Squares (ADF-GLS) unit root test (Elliott et al., 1996). The ADF-GLS tests show (Table A1 in Appendix) that the unit root hypothesis cannot be rejected at any significant level for each variable in the levels. Further investigations of the unit root hypothesis indicate that the first differenced variables are stationary at least at the 5\% level of significance. Hence all the series are found to be integrated of order I(1).

Next, the long-term relationship between carbon dioxide emissions and income (1) was estimated by means of OLS for each individual country, and based on disequilibrium error $\mu_{t}$ the parameters of the TAR and MTAR threshold autoregressive models (specifications for $\tau=0$ and estimated $\tau$ value) were estimated. Only for the case of Romania, Estonia and Slovenia both the null hypotheses of no cointegration $\left(H_{0}: \rho_{1}=\rho_{2}=0\right)$ and symmetric adjustment $\left(H_{0}: \rho_{1}=\rho_{2}\right)$ were rejected (Tables $\left.2-5\right)$, the rest of results were omitted but are available on request. For the remaining countries evidence for linear cointegration was found (see Table 5).

In the case of Romania it is seen that both $\rho$-coefficients in the MTAR framework ( $\tau=-0.019$ ) have negative signs which is the condition for $\mu_{t}$ to be stationary, and are significant at least at the $10 \%$ level in both regimes. Moreover the point estimate $\left|\rho_{1}\right|$ is smaller than $\left|\rho_{2}\right|$ which means that short-term adjustments towards the long-term equilibrium revert more quickly when the $\mathrm{CO}_{2}$ emissions show the momentum in the downwards direction and tend to persist more when $\mathrm{CO}_{2}$ emissions show the momentum in the upwards direction, i.e. emissions converge to their long-term equilibrium at the rate of $7.8 \%$ with a deviation below the threshold value $\tau$ and at a lower rate of $2 \%$ with a deviation above the threshold $\tau$ (Table 2 , MTAR, $\tau=-0.019$ ). In view of different environmental regulations (the Kyoto Protocol and the EU energy and climate obligations) introduced by the EU member countries, the quicker adjustment to equilibrium $\left(\left|\rho_{1}\right|>\left|\rho_{2}\right|\right)$ when $\mathrm{CO}_{2}$ emissions are above the long-term path (EKC) might have been expected. However, the results for Romania indicate that emissions are rather sticky downwards (are resistant to move down, $\left|\rho_{1}\right|<\left|\rho_{2}\right|$ ). At first 
sight it could seem that the effect of environmental pressure is not so evident but the inverted U-shape of the long-term relationship $\left(\alpha_{1}>0\right.$ and $\alpha_{2}<0$, Table 2) is evidence in favour of the EKC relation. Hence this result reflects sufficient activity of government policy directed into the reduction of $\mathrm{CO}_{2}$ emissions.

Table 2

Results of threshold cointegration test for Romania

\begin{tabular}{|c|c|c|c|c|}
\hline \multirow{2}{*}{$\begin{array}{c}\text { Parameters/ } \\
\text { statistics }\end{array}$} & \multicolumn{4}{|c|}{ Model } \\
\hline & $\begin{array}{c}T A R \\
\tau=0\end{array}$ & $\begin{array}{c}M T A R \\
\tau=0\end{array}$ & $\begin{array}{c}T A R \\
\tau=0.012\end{array}$ & $\begin{array}{c}M T A R \\
\tau=-0.019\end{array}$ \\
\hline$\rho_{1}$ & $-0.030(-2.40)^{* *}$ & $-0.018(-1.39)$ & $-0.030(-2.39)^{* *}$ & $\mathbf{- 0 . 0 2 0}(-1.97)^{*}$ \\
\hline$\rho_{2}$ & $-0.017(-1.10)$ & $-0.035(-2.40)^{* *}$ & $-0.017(-1.11)$ & $\mathbf{- 0 . 0 7 8}(-3.24)^{* * *}$ \\
\hline$\Phi \mu$ & 3.204 & 3.419 & 3.188 & 6.099* \\
\hline$F$ & $0.465[0.50]$ & $0.859[0.36]$ & $0.436[0.51]$ & $5.772[0.02]$ \\
\hline Lag & 2 & 2 & 2 & 2 \\
\hline $\mathrm{BIC}$ & -461.82 & -462.23 & -461.79 & -467.20 \\
\hline $\mathrm{LB}(3)$ & $1.52[0.68]$ & $0.92[0.82]$ & $1.51[0.68]$ & $0.01[0.99]$ \\
\hline \multicolumn{5}{|c|}{ Long-term relationship (an inverted U-shape: $\alpha_{1}>0, \alpha_{2}<0$ ) - GDP turning point $=1073$ (about 2004Q1) } \\
\hline Variables & Intercept & $\mathrm{GDP}_{t}$ & $\mathrm{GDP}_{t}^{2}$ & \\
\hline Coefficient & $-55.62^{* * * *}$ & $16.05^{* * *}$ & $-1.15^{* * *}$ & \\
\hline
\end{tabular}

Note: $\left({ }^{* *}\right),\left({ }^{* *}\right),\left({ }^{*}\right)$ indicate significance at $1 \%, 5 \%$ and $10 \%$. To test the parameter insignificance in the long-term relationship (H0: $\alpha_{2}=0$ and H0: $\alpha_{1}=0$ ) we applied onetailed test against the alternative hypotheses: $\mathrm{H} 1: \alpha_{2}<0$ and H1: $\alpha_{1}>0$, respectively. Critical values for $\Phi \mu$ statistics are from Enders, Siklos (2001). t-statistics for $\rho$ terms in parentheses. In brackets are $\mathrm{p}$-values for $\mathrm{F}$-statistics and Ljung-Box statistics. The lag length is selected so as to minimize the BIC.

Source: authors' calculations.

In the case of Estonia and Slovenia the $\rho$-coefficient of estimated models (see Tables 3 and 4) in the TAR framework are negative and significant in both regimes but have a different interpretation of adjustments to the long-term equilibrium because for Estonia $\left|\rho_{1}\right|<\left|\rho_{2}\right|$ and for Slovenia $\left|\rho_{1}\right|>\left|\rho_{2}\right|$. This means that $\mathrm{CO}_{2}$ emissions adjust more quickly to correct disequilibrium when they are above the long-term equilibrium $\left(\left|\rho_{1}\right|>\left|\rho_{2}\right|\right)$ in the case of Slovenia and when they are below the long-term relationship $\left(\left|\rho_{1}\right|<\left|\rho_{2}\right|\right)$ in the case of Estonia. At least for Slovenia the direction of adjustments ( $\rho$-coefficients) seems to be consistent with the expectation within the EKC hypothesis that the short-term deviations in emissions are 
corrected more quickly if they are too high. However, both in the case of Estonia and Slovenia the inverted U-shape of the EKC relationship does not hold, i.e. the long-term relationship is U-shaped (see the coefficient estimates, i.e. $\alpha_{1}<0$ and $\alpha_{2}>0$ in Tables 3 and 4) and hence the interpretation of adjustments coefficients should be considered in the context of a U-shaped relation. Such a shape assumes that $\mathrm{CO}_{2}$ emissions will be rising with per capita GDP (the second branch of the U-shaped curve) which sounds rather pessimistic with regard to the reduction of emissions. On the other hand, it is likely that in the future, with the increasing efficiency of environmental policy, the second branch of the U-shaped curve will flatten out and the long-term relationship between emissions and economic growth may be transformed into the inverted $\mathrm{N}$-shape (first falling, then rising and finally falling again) in these countries as a stricter environmental policy will be induced.

Table 3

Results of threshold cointegration test for Estonia

\begin{tabular}{|c|c|c|c|c|}
\hline \multirow[b]{2}{*}{$\begin{array}{c}\text { Parameters/ } \\
\text { statistics }\end{array}$} & \multicolumn{4}{|c|}{ Model } \\
\hline & $\begin{array}{c}T A R \\
\tau=0\end{array}$ & $\begin{array}{c}M T A R \\
\tau=0\end{array}$ & $\begin{array}{c}T A R \\
\tau=0.013\end{array}$ & $\begin{array}{l}\text { MTAR } \\
\tau=0.011\end{array}$ \\
\hline$\rho_{1}$ & $-\mathbf{0 . 0 5 0}(1.66)^{*}$ & $-0.103(2.60)^{* *}$ & $-0.049(1.62)$ & $-0.122(2.65)^{* *}$ \\
\hline$\rho_{2}$ & $-\mathbf{0 . 1 4 0}(4.58)^{* * *}$ & $-0.091(3.21)^{* *}$ & $-\mathbf{0 . 1 4 0}(4.62)^{* * *}$ & $-0.090(3.37)^{* * *}$ \\
\hline$\Phi \mu$ & $10.505 * * *$ & $6.363^{*}$ & $10.658^{* * *}$ & $6.624 *$ \\
\hline$F$ & $7.253[0.01] * * *$ & $0.100[0.75]$ & $7.292[0.01] * * *$ & $0.535[0.47]$ \\
\hline Lag & 2 & 2 & 2 & 2 \\
\hline BIC & -429.03 & -422.04 & -429.27 & -422.50 \\
\hline $\mathrm{LB}(3)$ & $1.43[0.70]$ & $0.26[0.97]$ & $1.60[0.66]$ & $0.33[0.95]$ \\
\hline \multicolumn{5}{|c|}{ Long-term relationship (a U-shape: $\alpha_{1}<0, \alpha_{2}>0$ ) } \\
\hline Variables & Intercept & $\mathrm{GDP}_{t}$ & $\mathrm{GDP}_{t}{ }^{2}$ & \\
\hline Coefficient & $44.61^{* * *}$ & $-11.53^{* * *}$ & $0.76^{* * * *}$ & \\
\hline
\end{tabular}

Note: see Table 2. To test the parameter insignificance in the long-term relationship $\left(\mathrm{H}_{0}: \alpha_{2}=0\right.$ and $\mathrm{H}_{0}: \alpha_{1}=0$ ) we applied one-tailed test against the alternative hypotheses: $\mathrm{H}_{1}: \alpha_{2}>0$ and $\mathrm{H}_{1}: \alpha_{1}<0$ respectively.

Source: authors' calculations.

For the rest of the countries (except Hungary) the linear cointegration between $\mathrm{CO} 2$ emissions and economic growth (Table 5) has been found which means (unlike threshold cointergration) that adjustments to equilibrium are corrected at each time and in the same way for deviations above or below the long-term relation. 
Table 4

Results of threshold cointegration test for Slovenia

\begin{tabular}{|c|c|c|c|c|}
\hline \multirow[b]{2}{*}{$\begin{array}{c}\text { Parameters / } \\
\text { statistics }\end{array}$} & \multicolumn{4}{|c|}{ Model } \\
\hline & $\begin{array}{c}T A R \\
\tau=0\end{array}$ & $\begin{array}{c}M T A R \\
\tau=0\end{array}$ & $\begin{array}{c}\boldsymbol{T A R} \\
\tau=0.037\end{array}$ & $\begin{array}{c}M T A R \\
\tau=-0.005\end{array}$ \\
\hline$\rho_{1}$ & $-0.064(2.79)^{* * *}$ & $-0.018(0.71)$ & $-\mathbf{0 . 1 1 3}(4.03)^{* * *}$ & $-0.023(1.06)$ \\
\hline$\rho_{2}$ & $0.002(0.078)$ & $-0.037(1.68)^{*}$ & $-\mathbf{0 . 0 0 2}(0.13)$ & $-0.037(1.46)$ \\
\hline$\Phi \mu$ & 4.055 & 1.5333 & $8.333 * *$ & 1.437 \\
\hline$F$ & $5.226[0.03]$ & $0.382[0.54]$ & $13.44[0.00]^{* * *}$ & $0.197[0.66]$ \\
\hline Lag & 2 & 2 & 2 & 2 \\
\hline $\mathrm{BIC}$ & -543.03 & -538.10 & -550.66 & -537.90 \\
\hline $\mathrm{LB}(3)$ & $6.54[0.09]$ & $5.52[0.14]$ & $4.59[0.20]$ & $6.13[0.11]$ \\
\hline \multicolumn{5}{|c|}{ Long-run relationship (a U-shape: $\alpha_{1}<0, \alpha_{2}>0$ ) } \\
\hline Variables & Intercept & $\mathrm{GDP}_{t}$ & $\mathrm{GDP}_{t}^{2}$ & \\
\hline Coefficient & $30.49 * *$ & $-7.32 * *$ & $0.45 * *$ & \\
\hline
\end{tabular}

Note: see Table 2 and Table 3

Source: authors' calculations.

Table 5

Parameter estimates of the long-term relationship (linear cointegration)

\begin{tabular}{|c|c|c|c|c|c|c|c|}
\hline \multirow{2}{*}{ Country } & \multicolumn{3}{|c|}{ Parameter estimates } & \multicolumn{3}{|c|}{ Cointegration test: ADF } & \multirow{2}{*}{$\begin{array}{l}\mathrm{GDP}_{\mathrm{TP}} \text { (date of } \\
\text { turning point) }\end{array}$} \\
\hline & Const & $G D P_{t}$ & $G D P_{t}^{2}$ & $\mathbf{n}$ & c & $\mathbf{c}+\mathbf{t}$ & \\
\hline \multicolumn{8}{|c|}{ Long-term relationship: an inverted U-shape: } \\
\hline Czech Republic & $-56.81^{* *}$ & $14.60^{* *}$ & $-0.92^{* *}$ & $-4.68^{* * *}$ & $-4.63^{* * *}$ & $-4.74^{* * *}$ & 2797 (2001Q1) \\
\hline Hungary & -9.38 & 2.77 & -0.19 & $-2.22^{* *}$ & -2.14 & -2.39 & \\
\hline Slovakia & $-14.86^{* *}$ & $4.19^{* *}$ & $-0.28^{* * *}$ & $-6.14^{* * *}$ & $-6.08^{* * *}$ & $-6.09^{* * *}$ & 1710 (before 1995Q1) \\
\hline \multicolumn{8}{|c|}{ Long-term relationship: a U-shape: $\alpha_{1}<0, \alpha_{2}>0$} \\
\hline Bulgaria & $25.09^{* *}$ & $-7.41^{* *}$ & $0.56^{* *}$ & $-5.79^{* * *}$ & $-5.75^{* * *}$ & $-5.77^{* * *}$ & \\
\hline Latvia & $35.71^{* * *}$ & $-9.94^{* * *}$ & $0.69^{* * *}$ & $-7.29^{* * *}$ & $-7.25^{* * *}$ & $7.18^{* * *}$ & \\
\hline Lithuania & $46.31^{* * *}$ & $-12.70^{* * *}$ & $0.87^{* * *}$ & $-6.43^{* * *}$ & $-6.38^{* * *}$ & $-6.47^{* * *}$ & \\
\hline Poland & $43.80^{* * *}$ & $-11.28^{* * *}$ & $0.74^{* * *}$ & $-5.92^{* * *}$ & $-5.87^{* * *}$ & $-5.83^{* * *}$ & \\
\hline
\end{tabular}

Note: $\left({ }^{* *}\right),\left({ }^{* *}\right),\left({ }^{*}\right)$ indicate significance at $1 \%, 5 \%$ and $10 \%$. To test the parameter insignificance in the long-term relationship $\left(\mathrm{H}_{0}: \alpha_{2}=0\right.$ and $\left.\mathrm{H}_{0}: \alpha_{1}=0\right)$ we applied one-tailed test against the alternative hypotheses: $\mathrm{H}_{1}: \alpha_{2}<0$ and $\mathrm{H}_{1}: \alpha_{1}>0$ (an inverted U-shape) and $\mathrm{H}_{1}: \alpha_{2}>0$ and $\mathrm{H}_{1}: \alpha_{1}<0$ (an U-shape) respectively. $\mathrm{c}+\mathrm{t}, \mathrm{c}, \mathrm{n}$ mean that the Dickey-Fuller regressions include an intercept and a linear trend, $\mathrm{c}$ - intercept but not a trend, $\mathrm{n}$ - without intercept and trend.

Source: authors' calculations. 

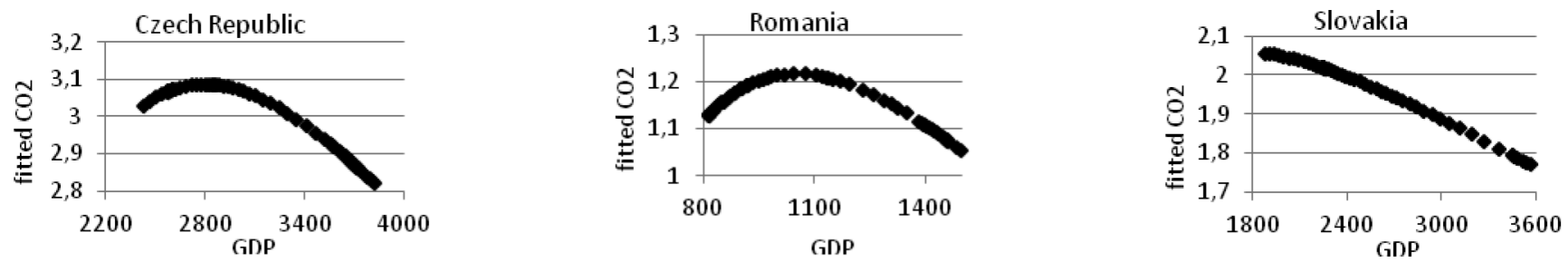

Figure 1. Graph of the fitted values of the estimated EKC results (an inverted U-shape)

Source: authors' calculations.
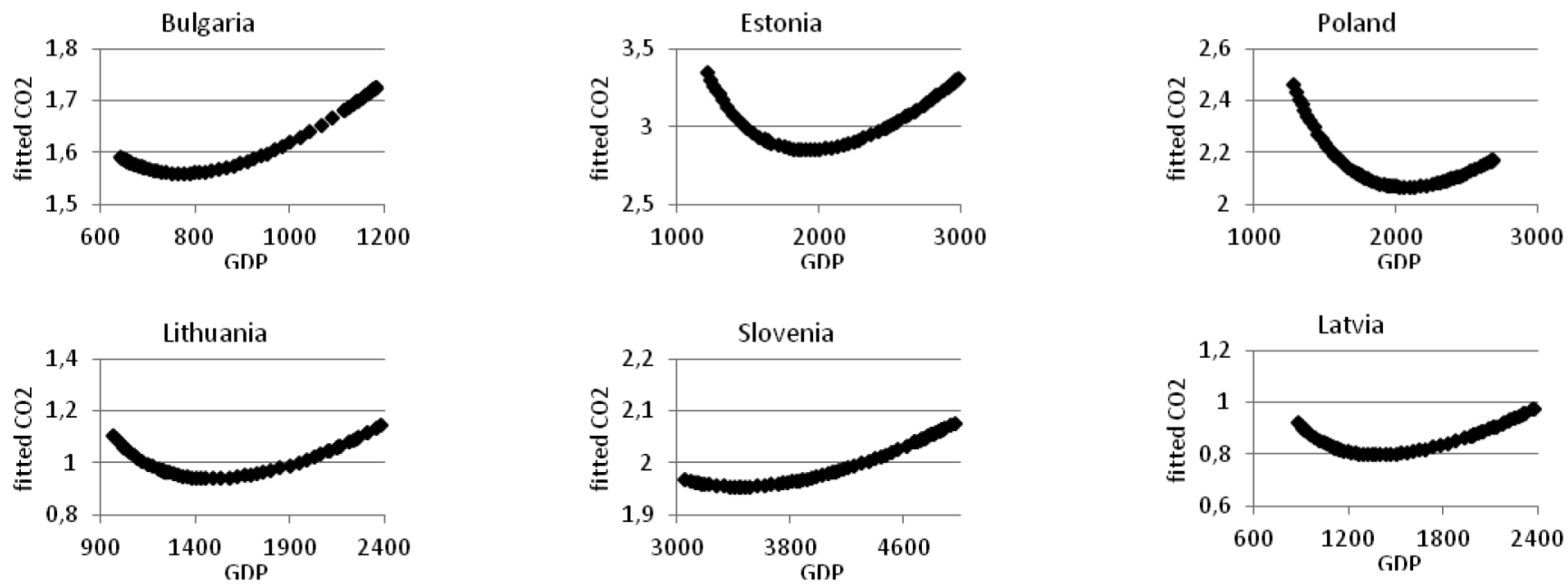

Figure 2. Graph of the fitted values of the estimated emissions-economic growth relationship results (a U-shape)

Source: authors' calculations. 
Having established the long-term relationship for $\mathrm{CO}_{2}$ emissions and economic growth (threshold and linear cointegration) we can analyze the estimation results and what they mean for the EKC hypothesis. Namely, the inverted U-shape of the EKC relation holds for the Czech Republic, Slovakia and Romania, and for the remaining countries (Bulgaria, Lithuania, Latvia, Poland, Estonia and Slovenia) in the long run the emission-economic growth relationship is U-shaped (the EKC hypothesis is not valid).

Table 6

The Granger causality results in the threshold error correction models - standard specification of the EKC

\begin{tabular}{|c|c|c|c|c|c|c|c|c|}
\hline \multirow{3}{*}{ 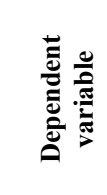 } & \multicolumn{7}{|c|}{ Source of causation } & \\
\hline & \multicolumn{3}{|c|}{ Short-term effects } & \multirow{2}{*}{ 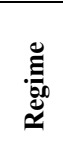 } & \multirow{2}{*}{$\begin{array}{c}\begin{array}{c}\text { Long-run } \\
\text { effect }\end{array} \\
E C T_{t-1} \\
\text { (t-Stud) }\end{array}$} & \multicolumn{3}{|c|}{ Interaction terms } \\
\hline & $\Delta C O 2_{t}$ & $\Delta Y_{t}$ & $\Delta Y_{t}^{2}$ & & & $\begin{array}{l}E C T_{t-1}, \\
\Delta C O 2_{t}\end{array}$ & $\begin{array}{l}E C T_{t-1}, \\
\Delta Y_{t}\end{array}$ & $\begin{array}{l}E C T_{t-1}, \\
\Delta Y_{t}^{2}\end{array}$ \\
\hline \multicolumn{9}{|c|}{ Long-term relationship: an inverted U-shape } \\
\hline \multicolumn{9}{|c|}{ Romania (MTAR, $\tau=-0.019$ ) } \\
\hline \multirow{2}{*}{$\Delta C O 2_{t}$} & \multirow[b]{2}{*}{-} & \multirow{2}{*}{1.35} & \multirow{2}{*}{1.35} & I & $1.93^{*}$ & - & $3.93^{* *}$ & $3.96^{* *}$ \\
\hline & & & & II & $3.02^{* * *}$ & - & $5.75^{* * *}$ & $5.70^{* * * *}$ \\
\hline \multirow{2}{*}{$\Delta Y_{t}$} & \multirow{2}{*}{0.67} & \multirow{2}{*}{-} & \multirow{2}{*}{0.75} & I & 1.02 & 0.75 & - & 1.84 \\
\hline & & & & II & 1.63 & 1.11 & - & 1.84 \\
\hline \multicolumn{9}{|c|}{ Long-term relationship: a U-shape } \\
\hline \multicolumn{9}{|c|}{ Estonia (TAR, $\tau=0.013$ ) } \\
\hline \multirow{2}{*}{$\Delta C O 2_{t}$} & \multirow{2}{*}{-} & \multirow{2}{*}{0.43} & \multirow{2}{*}{0.46} & I & 1.09 & - & 1.12 & 1.14 \\
\hline & & & & II & $6.45^{* * * *}$ & - & $14.97^{* * *}$ & $15.02^{* * *}$ \\
\hline \multirow{2}{*}{$\Delta Y_{t}$} & \multirow{2}{*}{1.19} & \multirow{2}{*}{-} & \multirow{2}{*}{1.43} & $\mathrm{I}$ & 0.08 & 1.09 & - & 1.14 \\
\hline & & & & II & $2.13^{* *}$ & $2.28^{*}$ & - & $2.80 * *$ \\
\hline \multicolumn{9}{|c|}{ Slovenia (TAR, $\tau=0.037$ ) } \\
\hline \multirow{2}{*}{$\Delta C O 2_{t}$} & \multirow{2}{*}{-} & \multirow{2}{*}{0.86} & \multirow{2}{*}{0.83} & $\mathrm{I}$ & $4.14 * * *$ & - & $6.68^{* * * *}$ & $6.64^{* * *}$ \\
\hline & & & & II & 0.58 & - & 0.68 & 0.67 \\
\hline \multirow{2}{*}{$\Delta Y_{t}$} & \multirow{2}{*}{2.35} & \multirow{2}{*}{-} & \multirow{2}{*}{1.93} & I & $3.93^{* * * *}$ & $7.80^{* * * *}$ & - & $7.08^{* * * *}$ \\
\hline & & & & II & $2.05^{*}$ & $3.98^{* *}$ & - & $2.65^{*}$ \\
\hline
\end{tabular}

Note: ${ }^{*},{ }^{* *},{ }^{* * *}$ denote the significance at the $10 \%, 5 \%$ and $1 \%$ level. Regime I refers to the state when emissions are above the long-term equilibrium (TAR model) or show the momentum in an upwards direction (MTAR model), regime II refers to the state when emissions are below the long-term equilibrium (TAR model) or show the momentum in a downwards direction (MTAR model). In Table 6 absolute values of t-Student statistic for long-term effect and Wald statistic values for short-term effects and interaction terms are given.

Source: authors' calculations

The fitted values of $\mathrm{CO} 2$ emissions for the observed values of real GDP for all countries are displayed in Figures 1 and 2. The turning points in the 
observed range of real GDP occurred at \$2797 in 2001Q1 for the Czech Republic and at $\$ 1073$ in 2004Q1 for Romania, and the turning points for Slovakia occurred outside the observed range of real GDP (before the starting point of the sample, i.e. 1995Q1) therefore only the falling branch of the EKC is observed. Summing up, there is strong evidence in favour of the EKC hypothesis (an inverted U-shape) in the Czech Republic, Slovakia and Romania. This means that the decoupling of economic growth from $\mathrm{CO} 2$ emissions appears (Azar et. al, 2002; Andreoni and Galmarini, 2012, also conclusions in this paper).Given the threshold cointegration results found in Tables 2-4, we proceeded with the Granger-causality test using the threshold error-correction model. The results of the Granger-causality test, based on the M-TAR-ECM models (Table 6) for Estonia, Romania and Slovenia show that there is no short-term causal relationships between emissions and income (GDP) since none of the explanatory variables in both equations are significant. With regard to the long-term causality we conclude that there is unidirectional Granger causality runs from economic growth to $\mathrm{CO}_{2}$ emission in both regimes for Romania, which jointly with the evidence of the inverted U-shape of the long-term relationship means that emissions are falling with an increase in the GDP and indicates the more efficient energy policy aimed at the abatement of emissions. There is also bidirectional long-term causality between emissions and economic growth for Estonia when emissions are below the long-term equilibrium (regime II) and for Slovenia when emissions are above the long-term equilibrium (regime I). This finding implies that both emissions and income contribute to short-term adjustment to re-establish the long-term equilibrium. The evidence of long-term bidirectional causality for Estonia and Slovenia together with the U-shape of the long-term relation means that high level of economic growth leads to a high level of $\mathrm{CO}_{2}$ emissions and vice versa. This has a number of implications for policy which should be more directed into energy efficiency improvements achieved through appropriate energy taxes and subsidies (i.e. appropriate environmental regulation).

\subsection{Extended specification of the EKC model and cointegration analysis}

To examine the impact of changes in energy consumption and technological changes on the nature of pollutant-economic growth relationship, we extended the standard EKC model by adding energy consumption or/and time trend and employed the same cointegration methodology and Granger causality tests to this extended version of the EKC model. The choice of the 
specification of the extended EKC model was determined basing on the parameter significance and stationarity of residuals. The results of the threshold cointegration are presented in Table 7.

Table 7

Results of threshold cointegration test - extended long-term relationship

\begin{tabular}{|c|c|c|c|c|}
\hline \multirow{3}{*}{$\begin{array}{c}\text { Parameters/ } \\
\text { statistics }\end{array}$} & Czech Republic & Bulgaria & Estonia & Slovenia \\
\hline & $M T A R, \tau=0$ & MTAR, $\tau=0$ & $M T A R, \tau=0$ & $M T A R, \tau=-0.004$ \\
\hline & \multicolumn{2}{|c|}{$\left|\rho_{1}\right|>\left|\rho_{2}\right|$} & \multicolumn{2}{|c|}{$\left|\rho_{1}\right|<\left|\rho_{2}\right|$} \\
\hline$\rho_{1}$ & $-0.178(3.99)^{* * *}$ & $-0.148(4.13)^{* * *}$ & $-0.051(1.72)^{*}$ & $-0.073(3.33)^{* * *}$ \\
\hline$\rho_{2}$ & $-0.040(0.98)$ & $-0.058(2.42)^{* *}$ & $-0.128(4.29)^{* * *}$ & $-0.149(3.53)^{* * *}$ \\
\hline$\Phi \mu$ & $7.99^{* * *}$ & $8.99^{* * *}$ & $9.20^{* * *}$ & $9.66^{* * *}$ \\
\hline$F$ & $6.60[0.01]^{* * *}$ & $6.63[0.01]^{* * *}$ & $5.31[0.02]^{* *}$ & $3.15[0.08]^{* * *}$ \\
\hline Lag & 4 & 2 & 2 & 2 \\
\hline $\mathrm{BIC}$ & -641.86 & -578.21 & -528.49 & -715.48 \\
\hline $\mathrm{LB}(3)$ & $6.74[0.08]$ & $2.94[0.40]$ & $0.50[0.92]$ & $0.40[0.94]$ \\
\hline \multicolumn{5}{|c|}{ Long-term relationship } \\
\hline & An inverted U-shape & A U-shape & A U-shape & A U-shape \\
\hline Intercept & $-53.68^{* * * *}$ & $10.53^{* * *}$ & $11.61^{* * *}$ & $13.66^{* * *}$ \\
\hline $\mathrm{GDP}_{t}$ & $12.28^{* * *}$ & $-5.23^{* * *}$ & $-4.38^{* * *}$ & $-4.75^{* * *}$ \\
\hline $\mathrm{GDP}_{t}^{2}$ & $-0.74^{* * *}$ & $0.39^{* * *}$ & $0.28^{* * *}$ & $0.30^{* * *}$ \\
\hline $\mathrm{E}_{t}$ & $0.61^{* * *}$ & $1.16^{* * *}$ & $0.94^{* * *}$ & $0.87^{* * *}$ \\
\hline Time & $-0.01^{* * *}$ & - & - & $-0.003^{* * *}$ \\
\hline
\end{tabular}

Note: see Table 2 and Table 5

Source: authors' calculations.

Table 7 displays the results of the Enders-Skiklos cointegration test for countries for which both the null hypothesis of no cointegration and the null of symmetric adjustment are rejected (at least at the $10 \%$ significance level). Unlike the results in Tables 3-5, we present only the best threshold autoregressive models (with the MTAR adjustment process) which are selected using the BIC criterion, residual diagnostics and significance of parameters. It is seen in Table 10 that the inclusion of energy consumption or/and time trend into the long-term relationship changed the results in comparison with the standard specification of the EKC, i.e. evidence for threshold cointegration is found not only for Estonia and Slovenia (like in the standard EKC model), but also for the Czech Republic and Bulgaria (for which linear cointegration was observed in the standard EKC model), and for Romania the linear cointegration occurred, as opposed to the threshold cointegration in the standard EKC model. For the case of the Czech Republic 
and Bulgaria, the point estimates $\left|\rho_{1}\right|$ are greater than $\left|\rho_{2}\right|$ which suggests that any deviation from the long-term relationship is corrected quicker when per capita $\mathrm{CO}_{2}$ emissions show the momentum in the upwards direction and tend to persist when the emissions show the momentum in a downwards direction. Such results indicate that $\mathrm{CO}_{2}$ emissions are more 'sticky upwards' (resistant to move up) and point to the significant effect of environmental pressure. In part this may reflect the strong role of environmental regulation and the efficiency of government policy aimed at reducing $\mathrm{CO}_{2}$ emissions and meeting the EU energy and climate obligations. Such interpretation is justified only in the case of the Czech Republic for which the signs of longterm coefficients on $G D P_{t}$ and $G D P_{t}^{2}$ are in line with the EKC model (an inverted U-shape), i.e. $\alpha_{1}>0, \alpha_{2}<0$ (see parameter estimates of the longterm relationship in Table 7). While for Bulgaria the signs of these coefficients are consistent with the U-shaped relationship $\alpha_{1}<0, \alpha_{2}>0$, but not with the EKC. Therefore, the faster speed of adjustment for emission deviations from the long-term equilibrium in regime I, i.e. $\left(\left|\rho_{1}\right|>\left|\rho_{2}\right|\right)$, may only indicate some potential for reverting the shape of long-term relationship into that which is consistent with the inverted $\mathrm{N}$-shape (with regard to signs of coefficients on $G D P_{t}$ and $G D P_{t}^{2}$ ) as the efficiency of environmental policy will grow.

For Estonia and Slovenia the point estimates $\left|\rho_{1}\right|$ are smaller than $\left|\rho_{2}\right|-$ see Table 7 - which means that deviations in $\mathrm{CO}_{2}$ emissions from long-term equilibrium revert more quickly when $\mathrm{CO}_{2}$ emissions show the momentum in a downwards direction and tend to persist when emissions show the momentum in an upwards direction. In other words, $\mathrm{CO}_{2}$ emissions in these countries remain for a longer period of time in the regime of higher emissions. When we combine this interpretation with the long-term relationship which has signs on $G D P_{t}$ and $G D P_{t}^{2}$ like in the U-shaped relationship $\left(\alpha_{1}<0, \alpha_{2}>0\right)$, we may expect that these countries will experience higher $\mathrm{CO}_{2}$ emissions with per capita income unless the environmental policy becomes more effective.

For the remaining countries the linear cointegration of emissioneconomic growth relationship was found (Tables 8 and 9). In the case of Hungary and Romania the long-term relationships remain correctly signed as in the standard specification of the EKC (Table 5), suggesting the relationship is reasonably robust. This means that $\mathrm{CO} 2$ emissions in these countries are first rising and then falling with per capita GDP. It is worth 
Table 8

Parameter estimates of extended long-term relationship (linear cointegration)

\begin{tabular}{l|c|c|c|c|c|c|c|c}
\hline \multirow{2}{*}{ Country } & \multicolumn{7}{c|}{ Parameter estimates } & \multicolumn{2}{c}{ Cointegration test: ADF-GLS } \\
\cline { 2 - 9 } & Intercept & $\mathbf{G D P}_{\boldsymbol{t}}$ & $\mathbf{G D P}_{\boldsymbol{t}}{ }^{2}$ & $\mathbf{E}_{\boldsymbol{t}}$ & time & $\mathbf{n}$ & $\mathbf{c}$ & $\mathbf{c}+\mathbf{t}$ \\
\hline \multicolumn{7}{c}{ Long-term relationship: an inverted U-shape: $\alpha_{1}>0, \alpha_{2}<0$} \\
\hline Hungary & $-26.69^{* * *}$ & $4.996^{* * *}$ & $-0.302^{* * *}$ & $1.032^{* * *}$ & $-0.004^{* * *}$ & $-10.75^{* * *}$ & $-10.71^{* * *}$ & $-10.65^{* * *}$ \\
\hline Poland & $-8.74^{* *}$ & 0.9515 & -0.071 & $0.997^{* * *}$ & - & $-8.71^{* * *}$ & $-8.64^{* * *}$ & $-8.59^{* * *}$ \\
\hline Romania & $-34.03^{* * *}$ & $8.005^{* * *}$ & $-0.555^{* * *}$ & $0.905^{* * *}$ & $-0.004^{* * *}$ & $-7.80^{* * *}$ & $-7.73^{* * *}$ & $-7.69^{* * *}$ \\
\hline Slovakia & $-12.84^{* *}$ & $2.07^{*}$ & -0.11 & $0.65^{* * *}$ & $-0.01^{* * *}$ & $-11.58^{* * *}$ & $-11.49^{* * *}$ & $-11.43^{* * *}$ \\
\hline \multicolumn{7}{|c|}{${\text { Long-term relationship: a U-shape: } \alpha_{1}<0, \alpha_{2}>0}$} \\
\hline Latvia & 5.597 & $-3.112^{* * *}$ & $0.203^{* * *}$ & $0.991^{* * *}$ & - & $-10.55^{* * *}$ & $-10.51^{* * *}$ & $-10.44^{* * *}$ \\
\hline Lithuania & $47.00^{* * *}$ & $-13.38^{* * *}$ & $0.915^{* * *}$ & $0.289^{* * *}$ & - & $-6.78^{* * *}$ & $-6.74^{* * *}$ & $-6.75^{* * *}$ \\
\hline
\end{tabular}

Note: see Table 5

Source: authors' calculations.

Table 9

Summarized results of cointegration analysis for the CEE countries - extended specification of the pollutant-income relationship

\begin{tabular}{c|c|c|c|c}
\hline \multirow{2}{*}{$\begin{array}{c}\text { Type of } \\
\text { cointegration }\end{array}$} & \multicolumn{3}{|c}{ Shape of long-term pollutant-income relationship } \\
\cline { 2 - 5 } & \multicolumn{2}{|c|}{ Standard specification } & \multicolumn{2}{c}{ Extended specification } \\
\hline \multirow{2}{*}{ Threshold } & $\begin{array}{c}\text { The inverted } \\
\text { U-shape } \\
\alpha_{1}>0, \alpha_{2}<0\end{array}$ & $\begin{array}{c}\text { The U-shape } \\
\alpha_{1}<0, \alpha_{2}>0\end{array}$ & $\begin{array}{c}\text { The inverted } \\
\text { U-shape } \\
\alpha_{1}>0, \alpha_{2}<0\end{array}$ & $\begin{array}{c}\text { The U-shape } \\
\alpha_{1}<0, \alpha_{2}>0\end{array}$ \\
\hline Linear & Romania & Estonia, Slovenia & Czech Republic & $\begin{array}{c}\text { Bulgaria, Estonia, } \\
\text { Slovenia }\end{array}$ \\
\hline & $\begin{array}{c}\text { Czech Republic, } \\
\text { Slovakia }\end{array}$ & $\begin{array}{c}\text { Bulgaria, Lithuania, } \\
\text { Latvia, Poland }\end{array}$ & $\begin{array}{c}\text { Hungary, } \\
\text { Romania, }\end{array}$ & Latvia, Lithuania \\
\hline
\end{tabular}

Source: authors' calculations.

noting that in the case of Poland the inclusion of energy consumption into the long-term relationship caused a change in the signs and significance coefficients on $G D P_{t}$ and $G D P_{t}^{2}$ in comparison to the standard specification of EKC (see Tables 2 and 6), i.e. now coefficients are signed like in the inverted U-shape of long-term relationship but are insignificant. This finding seems to suggest that energy consumption is of great relevance in explaining $\mathrm{CO}_{2}$ emissions in the case of Poland.

For Latvia and Lithuania the long-term relationships are signed as in the standard specification of the EKC (Tables 2 and 6), i.e. the signs of coefficients on $G D P_{t}$ and $G D P_{t}^{2}$ are consistent with the U-shaped relationship which indicates that emissions are first falling and then rising with per capita GDP. 
Table 10

The Granger causality results in the threshold error correction models extended specification of the EKC

\begin{tabular}{|c|c|c|c|c|c|c|c|c|c|c|}
\hline \multirow{3}{*}{ 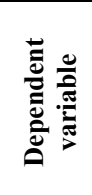 } & \multicolumn{10}{|c|}{ Source of causation } \\
\hline & \multicolumn{4}{|c|}{ Short-term effects } & \multirow{2}{*}{ 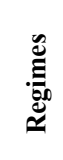 } & \multirow{2}{*}{$\begin{array}{c}\begin{array}{c}\text { Long-run } \\
\text { effects }\end{array} \\
E C T \\
\text { (t-Stud) }\end{array}$} & \multicolumn{4}{|c|}{ Interaction terms } \\
\hline & $\Delta C O 2_{t}$ & $\Delta Y_{t}$ & $\Delta Y_{t}^{2}$ & $\Delta E_{t}$ & & & $\begin{array}{l}E C T, \\
\Delta C O 2_{t}\end{array}$ & $\begin{array}{c}E C T \\
\Delta Y_{t}\end{array}$ & $\begin{array}{c}E C T \\
\Delta Y_{t}^{2}\end{array}$ & $\begin{array}{c}E C T \\
\Delta E_{t}\end{array}$ \\
\hline \multicolumn{11}{|c|}{ Long-term relationship: an inverted U-shape } \\
\hline \multicolumn{11}{|c|}{ Czech Republic (M-TAR, $\tau=-0.003)$} \\
\hline \multirow{2}{*}{$\triangle C O 2_{t}$} & \multirow{2}{*}{-} & \multirow{2}{*}{$3.08^{*}$} & \multirow{2}{*}{$3.09^{*}$} & \multirow{2}{*}{0.30} & I & $1.83^{*}$ & - & $3.12^{* *}$ & $3.11^{* *}$ & 1.17 \\
\hline & & & & & II & 0.97 & - & $2.27 *$ & $2.28^{*}$ & 0.45 \\
\hline \multirow{2}{*}{$\Delta Y_{t}$} & \multirow{2}{*}{0.09} & \multirow{2}{*}{-} & \multirow{2}{*}{1.53} & \multirow{2}{*}{0.17} & I & 1.06 & 0.52 & - & 1.39 & 0.68 \\
\hline & & & & & II & 1.12 & 0.56 & - & 1.41 & 0.99 \\
\hline \multicolumn{11}{|c|}{ Long-term relationship: an U-shape } \\
\hline \multicolumn{11}{|c|}{ Bulgaria (M-TAR, $\tau=0)$} \\
\hline \multirow{2}{*}{$\triangle C O 2_{t}$} & \multirow{2}{*}{-} & \multirow{2}{*}{0.909} & \multirow{2}{*}{0.903} & \multirow{2}{*}{1.306} & I & $1.82^{*}$ & - & 1.83 & 1.84 & 1.22 \\
\hline & & & & & II & $2.84^{* * * *}$ & - & $3.26^{* *}$ & $3.29^{* *}$ & $2.77^{* *}$ \\
\hline \multirow{2}{*}{$\Delta Y_{t}$} & \multirow{2}{*}{1.01} & \multirow{2}{*}{-} & \multirow{2}{*}{1.35} & \multirow{2}{*}{1.26} & I & 0.36 & 0.96 & - & 0.93 & 1.24 \\
\hline & & & & & II & $2.61^{* *}$ & $3.83^{* *}$ & - & $2.73^{*}$ & $3.47^{* *}$ \\
\hline \multicolumn{11}{|c|}{ Estonia $(\mathrm{M}-\mathrm{TAR}, \tau=0)$} \\
\hline$\triangle C O 2$ & - & 0.96 & 101 & 060 & $\mathrm{II}$ & 1.65 & $\begin{array}{llll}- & & & \end{array}$ & 1.25 & 1.27 & 1.03 \\
\hline$\Delta \mathrm{C} D \mathrm{z}_{t}$ & - & 0.96 & 1.01 & 0.60 & II & $3.18^{* * * *}$ & - & $4.64^{* * *}$ & $4.67^{* * *}$ & $4.16^{* * *}$ \\
\hline$\Delta Y$ & 211 & - & & 115 & I & 0.43 & 1.41 & - & 0.85 & 0.81 \\
\hline$\Delta I_{t}$ & 2.11 & - & 1.15 & 1.15 & II & 1.51 & $2.28^{*}$ & - & $2.70^{*}$ & 1.98 \\
\hline & & & & Slovenia & $(\mathrm{M}-\mathrm{T}$ & $\mathrm{R}, \tau=-0.0$ & & & & \\
\hline$\triangle C O 2$ & - & 092 & 082 & $317^{* *}$ & $\mathrm{I}$ & 0.77 & - & 0.74 & 0.73 & $2.65^{* *}$ \\
\hline$\Delta E v_{t}$ & - & 0.92 & 0.82 & 0.17 & II & $1.89^{*}$ & - & 1.22 & 1.20 & $2.85^{* *}$ \\
\hline$\Delta Y$ & 1.53 & - & $2.24^{*}$ & $312^{* *}$ & $\mathrm{I}$ & 0.94 & 1.76 & - & 1.82 & $2.65^{* *}$ \\
\hline$\Delta I_{t}$ & 1.03 & - & 2.24 & & II & 1.41 & 1.29 & $\begin{array}{llll}- & & & \end{array}$ & 1.92 & $2.61^{* *}$ \\
\hline
\end{tabular}

Note: see Table 6

Source: authors' calculations.

Having included the energy consumption and/or time trend into emission-economic growth relationship (4) and estimated the threshold error correction models (8)-(9), the importance of energy consumption in restoring the long-term equilibrium has been exhibited especially for Bulgaria, Estonia and Slovenia (significance of interaction terms $E C T, \Delta E_{t}$ in Table 10). There is unidirectional long-term causality running from GDP and energy consumption to $\mathrm{CO}_{2}$ emissions since the coefficient of ECT in the emissions equation is significant at least at the $10 \%$ level when emissions show the momentum in a downwards direction (regime II) for Estonia and Slovenia. This implies that GDP and energy consumption interact in the short run to re-establish the long-term equilibrium after a change in 
emissions, however in the case of Slovenia the long-term effect of GDP is rather weak (insignificance of interaction terms $E C T, \Delta Y_{t} ; E C T, \Delta Y_{t}^{2}$ ). In the case of Bulgaria this long-term causality is bidirectional in regime II (due to the significance of the coefficient of ECT in the $\mathrm{CO}_{2}$ and GDP equations). In the case of the Czech Republic it can be seen that the coefficient of ECT is significant at the $10 \%$ level in the emissions equation for regime I, i.e. when emissions show the momentum in an upwards direction. This means that GDP and energy consumption interact in a dynamic fashion to restore the long-term equilibrium. However, the nonsignificance of the Wald statistics for energy consumption indicates that it is exogenous in the system, implying that GDP bears the burden of the shortterm adjustment to long-term equilibrium.

In terms of the short-term causality it can be seen from the emissions equation in the case of the Czech Republic that economic growth Grangercauses emissions, and from the emissions and GDP equations in the case of Slovenia - that energy Granger-causes both emissions and GDP (see Table 10).

These findings indicate that the addition of energy consumption has affected the results in terms of the presence of threshold cointegration (for Bulgaria and Romania) and the pattern of non-linear causal links between variables, i.e. energy consumption turned out to be an important factor especially in countries with the U-shape of long-term relationship between emissions and economic growth.

\section{CONCLUSIONS AND POLICY IMPLICATIONS}

In this paper we examined the long-term equilibrium relationship between $\mathrm{CO}_{2}$ emission and economic growth (the EKC hypothesis) in an asymmetric framework using the non-linear threshold cointegration approach for the CEE countries. First we tested for the presence of threshold cointegration between per capita greenhouse gas emissions and per capita income (real GDP) with regard to the standard EKC relation, and then to test the robustness of the results we considered the extended EKC hypothesis by adding energy consumption or/and time trend to the standard EKC model.

With regard to the standard EKC we found a non-linear cointegration between $\mathrm{CO}_{2}$ emissions and economic growth for Romania, Estonia and Slovenia. However, only for Romania the inverted U-shape of a long-term relationship between emissions and economic growth was observed what may be treated as evidence in favour of the EKC relation. Moreover, this 
finding can be interpreted in terms of effective environmental policy directed into the reduction of $\mathrm{CO}_{2}$ emissions. For Estonia and Slovenia the long-term relation is U-shaped which indicates that the EKC relationship does not hold. This result may reflect the weak role of environmental regulation or the insufficient activity of government policy in emission reduction efforts. For the remaining countries (except Hungary) the linear cointegration between emissions and economic growth was found, but only for the Czech Republic and Slovakia the inverted U-shape of long-term relationship was observed which suggested that the EKC hypothesis was valid.

It is worth noting that evidence for the EKC hypothesis was found only for those countries for which absolute decoupling occurred (emissions have been declining in absolute terms systematically for several years and economic growth has been increasing or stable) - see Table 11. Moreover, the EKC hypothesis holds for countries having a diversified energy consumption mix (with a significant share of nuclear and renewable energy and also a smaller share of solid fuels; see Table 1), which was indicated in the Analysis of Central Europe's Energy Sector (prepared by Ernst \& Young, 2013) as one of the key challenges concerning the emissions reduction and environmental protection in the Central and Eastern European countries. This decoupling effect may be the measure of the effective implementation of environmental policy in these countries. Such a policy aimed at the gradual reduction in energy intensity of industrial processes, restructuring in the industrial sectors, technological development and increasing the renewables share in energy mix-structure, resulted in the decline of $\mathrm{CO}_{2}$ emissions.

For the countries with a U-shaped relationship between $\mathrm{CO}_{2}$ emissions and economic growth (Table 9) a relative decoupling is observed, i.e. the growth of $\mathrm{CO}_{2}$ emissions is slower (but without a decline in absolute terms) than economic growth (except Slovenia for which the absolute decoupling seems to occur during the last four years, but it is not accompanied by the inverted U-shape of the long-term relation, Table 11). It is symptomatic that these countries have also diversified energy production and consumption mix (except for Poland and Estonia with solid fuels accounting for the highest share of total production and consumption; Table 1) but did not exhibit a significant decline in $\mathrm{CO}_{2}$ emissions. Several reasons are given (Stern, 2006) as to why $\mathrm{CO}_{2}$ emissions do not tend to fall as economies grow and as a consequence do not follow the EKC relationship, e.g. the globalisation which increases trade between countries and raises transport needs for products, and therefore $\mathrm{CO}_{2}$ emissions, growing demand for some 
carbon-intensive goods and services such as air transport, growing car transport in many developing countries increases $\mathrm{CO}_{2}$ emissions. Moreover, in the case of the Central and Eastern European countries which have been undergoing both economic and political transformation since 1990, these reasons additionally lie in the outdated energy infrastructure and the heavy burden of restructuring the energy sectors and high-polluting industrial sectors, together with the high costs of implementing new technologies, low environmental consciousness and insufficient environmental regulations which just have been changing since the decision of these countries to access the European Union. In this context, the lack of the decoupling effect may also be connected with the efficiency of the environmental policy not giving enough incentives to reduce $\mathrm{CO}_{2}$ emissions. For example, under phase two of the European Union's Emissions Trading System the Eastern European countries were granted allowances for $\mathrm{CO}_{2}$ emissions for free, hence it contributed to not treating the $\mathrm{CO} 2$ permit as a commodity worth an effort at reduction. Therefore in phase three of the Emissions Trading System (ETS

Table 11

GDP and $\mathrm{CO}_{2}$ emissions indices $(2005=100)$

\begin{tabular}{l|c|c|c|c|c|c|c|c}
\hline & & $\mathbf{2 0 0 6}$ & $\mathbf{2 0 0 7}$ & $\mathbf{2 0 0 8}$ & $\mathbf{2 0 0 9}$ & $\mathbf{2 0 1 0}$ & $\mathbf{2 0 1 1}$ & $\mathbf{2 0 1 2}$ \\
\hline Bulgaria & $\mathrm{GDP}$ & 1.07 & 1.17 & 1.24 & 1.19 & 1.20 & 1.24 & 1.25 \\
\hline & $\mathrm{CO}_{2}$ & 1.05 & 1.12 & 1.09 & 0.94 & 0.98 & 1.11 & 1.02 \\
\hline Czech Rep. & $\mathrm{GDP}$ & 1.07 & 1.12 & 1.14 & 1.08 & 1.10 & 1.12 & 1.11 \\
\hline & $\mathrm{CO}_{2}$ & 1.00 & 1.00 & $\mathbf{0 . 9 5}$ & $\mathbf{0 . 8 9}$ & $\mathbf{0 . 9 0}$ & $\mathbf{0 . 8 9}$ & $\mathbf{0 . 8 5}$ \\
\hline Estonia & $\mathrm{GDP}$ & 1.11 & 1.20 & 1.14 & 0.98 & 1.00 & 1.09 & 1.14 \\
\hline & $\mathrm{CO}$ & 0.97 & 1.17 & 1.07 & 0.88 & 1.11 & 1.15 & 1.07 \\
\hline Hungary & $\mathrm{GDP}$ & 1.04 & 1.05 & 1.06 & 0.99 & 1.00 & 1.02 & 1.01 \\
\hline & $\mathrm{CO}$ & 1.00 & $\mathbf{0 . 9 8}$ & $\mathbf{0 . 9 5}$ & $\mathbf{0 . 8 6}$ & $\mathbf{0 . 8 8}$ & $\mathbf{0 . 8 5}$ & $\mathbf{0 . 7 8}$ \\
\hline Latvia & $\mathrm{GDP}$ & 1.13 & 1.25 & 1.22 & 1.06 & 1.06 & 1.13 & 1.20 \\
\hline & $\mathrm{CO}$ & 1.09 & 1.15 & 1.09 & 1.00 & 1.18 & 1.09 & 1.06 \\
\hline Lithuania & $\mathrm{GDP}$ & 1.09 & 1.23 & 1.27 & 1.10 & 1.14 & 1.23 & 1.30 \\
\hline & $\mathrm{CO} 2$ & 1.05 & 1.14 & 1.12 & 0.98 & 1.05 & 1.10 & 1.12 \\
\hline Poland & $\mathrm{GDP}$ & 1.06 & 1.14 & 1.18 & 1.21 & 1.26 & 1.32 & 1.35 \\
\hline & $\mathrm{CO}_{2}$ & 1.05 & 1.05 & 1.02 & 0.98 & 1.05 & 1.04 & 1.01 \\
\hline Romania & $\mathrm{GDP}$ & 1.09 & 1.18 & 1.29 & 1.22 & 1.21 & 1.25 & 1.26 \\
\hline & $\mathrm{CO}_{2}$ & 1.07 & 1.07 & 1.04 & $\mathbf{0 . 8 9}$ & $\mathbf{0 . 8 5}$ & $\mathbf{0 . 9 1}$ & $\mathbf{0 . 9 1}$ \\
\hline Slovakia & $\mathrm{GDP}$ & 1.08 & 1.20 & 1.26 & 1.19 & 1.25 & 1.28 & 1.30 \\
\hline & $\mathrm{CO}_{2}$ & $\mathbf{0 . 9 9}$ & $\mathbf{0 . 9 5}$ & $\mathbf{0 . 9 6}$ & $\mathbf{0 . 8 7}$ & $\mathbf{0 . 8 8}$ & $\mathbf{0 . 8 8}$ & $\mathbf{0 . 8 3}$ \\
\hline Slovenia & $\mathrm{GDP}$ & 1.05 & 1.12 & 1.16 & 1.06 & 1.06 & 1.07 & 1.04 \\
\hline & $\mathrm{CO}_{2}$ & 1.00 & 1.01 & 1.07 & 0.94 & 0.94 & 0.94 & 0.90 \\
\hline
\end{tabular}

Source: based on Eurostat data. 
III) the EU decided to move towards a system based on the full auctioning of $\mathrm{CO} 2$ permits.

When we employed the same threshold cointegration methodology with regard to the extended EKC model, we found that the addition of energy consumption or/and time trend has affected the results because the threshold cointegration with asymmetric adjustment has been observed not only for Estonia and Slovenia (like in the standard EKC model), but also for the Czech Republic and Bulgaria (for which the linear cointegration was confirmed in the standard EKC model), and for Romania the linear cointegration occurred instead of the threshold cointegration in the standard EKC model. For Bulgaria, Estonia and Slovenia the signs of coefficients (on $G D P$ ) in the long-term relationship are in line with the U-shaped curve, indicating the insufficient activity of government directed into the reduction of $\mathrm{CO}_{2}$ emissions. While for the Czech Republic the coefficient signs on $G D P$ are in line with the EKC hypothesis (inverted U-shape) suggesting the efficiency of environmental policy in emission reduction efforts.

For countries for which the linear cointegration between emissions, economic growth and energy consumption was found (in the framework of extended specification of the EKC model) only for Hungary, Romania and Slovakia the signs of coefficients on GDP in the long-term relation were in line with the inverted U-shape of long-term relation and additionally the decoupling of economic growth from emissions was observed (absolute decoupling) suggesting an effective environmental policy.

The results obtained in the paper suggest that the EKC model needs to be estimated using an approach accounting for asymmetric adjustment and also incorporating different energy aspects, such as energy consumption and technological change to reflect their contribution to the emissions. These findings also indicate that the investigation of the EKC hypothesis can be not only treated as evidence that the decoupling of economic growth from emissions occurs, but also as a useful tool to evaluate the effectiveness of the policy implemented to reduce emissions.

\section{REFERENCES}

Analysis of Central Europe's Energy Sector (Prague Report), prepared by Ernst \& Young, 2013, http://www.ey.com/Publication/vwLUAssets/EY_Raport_CEEP_2013/\$FILE/ CEEP_raport_2013.pdf.

Andreoni, V., Galmarini, S., Decoupling Economic Growth from Carbon Dioxide Emissions: A Decomposition Analysis of Italian Energy Consumption, "Energy", 44, pp. 682-691, 2012. 
Azar, C., Holmberg, J., Karlson, S., Decoupling : Past Trends and Prospects for the Future, University of Götenberg, Department of Environmental Economics, Stockholm, May 2002.

Acaravci, A., Ozturk, I., On the Relationship between Energy Consumption, CO2 Emissions and Economic Growth in Europe, "Energy", 35, pp. 5412-5420, 2010.

Agras, J., Chapman, D., A Dynamic Approach to the Environmental Kuznets Curve Hypothesis, "Ecological Economics", 28, pp. 267-277, 1999.

Analysis of Central Europe's Energy Sector (Prague Report), prepared by Ernst \& Young, 2013, http://www.ey.com/Publication/vwLUAssets/EY_Raport_CEEP_2013/\$FILE/ CEEP_raport_2013.pdf.

Ang, J., CO2 Emissions, Energy Consumption, and Output in France, "Energy Policy", 35, pp. 4772-78, 2007.

Annabelle, G., A Discussion on Decoupling Economic Growth from the Emissions of Carbon Dioxide, Environment Waikato Technical Report, February 2007.

Antczak, E., Degradation of Air vs. Quality of Life - Spatial Panel Analysis, "Folia Oeconomica Acta Universitatis Lodziensis", 292, pp. 117-129, 2013.

Antczak, E., Suchecka, J., Spatial Autoregressive Panel Data Models Applied to Evaluate the Levels of Sustainable Development in European Countries, "Folia Oeconomica Acta Universitatis Lodziensis", 252, pp. 21-44, 2011.

Apergies, N., Payne, J. E., CO2 Emissions, Energy Usage and Output in Central America, "Energy Policy", 37, pp. 3282-3286, 2009.

Apergies, N., Payne, J. E., The Emissions, Energy Consumption, and Growth Nexus: Evidence from the Commonwealth of Independent States, "Energy Policy", 38, pp. 650-655, 2010.

Asafu-Adjaye, J., The Relationship Between Energy Consumption, Energy Prices and Economic Growth: Time Series Evidence from Asian Developing Countries, "Energy Economics", 22, pp. 615-625, 2000.

Baek, J., A Panel Cointegration Analysis of CO2 Emissions, Nuclear Energy and Income in Major Nuclear Generating Countries, “Applied Energy”, 145, pp. 133-138, 2015.

Baek, J., Kim, H. S., Trade Liberalization, Economic Growth, Energy Consumption and the Environment: Time Series Evidence from G-20 Countries, "Journal of East Asian Economic Integration", 15, pp. 3-32, 2011.

Balke, N. S., Fomby, T. B., Threshold Cointegration, "International Economic Review", 38, pp. 627-645, 1997.

Carson, R. T., The Environmental Kuznets Curve: Seeking Empirical Regularity and Theoretical Structure, "Review of Environmental Economics and Policy", 4, pp. 3-23, 2010.

Chan, S.-L., Consistency and Limiting Distribution of the Least Squares Estimator of a Threshold Autoregressive Model, "The Annals of Statistics", 21, pp. 520-533, 1993.

Cole, M. A., Rayner, A. J., Bates, J. M., The Environmental Kuznets Curve: An Empirical Analysis, "Environment and Development Economics", 2, pp. 401-416, 1997.

Cole, M. A., Trade, the Pollution Haven Hypothesis and Environmental Kuznets Curve: Examining the Linkages, "Ecological Economics", 48, pp. 71-81, 2004.

Coondoo, D., Dinda, S., Carbon Dioxide Emission and Income: A Temporal Analysis of Cross-country Distributional Patterns, "Ecological Economics", 65, pp. 375-385, 2008. 
Dasgupta, S., Laplante; B., Wang, H., Wheeler, D., Confronting the Environmental Kuznets Curve, "The Journal of Economic Perspectives", 16, pp. 147-168, 2002.

Dinda, D., Environmental Kuznets Curve Hypothesis: a Survey, "Ecological Economics", 49, pp. 431-455, 2004.

Dinda, S., Coondoo, D., Income and Emission: A Panel Data-based Cointegration Analysis, "Ecological Economics", 57, pp. 167-181, 2006.

Dinda, S., Coondoo, D., Pal, M., Air Quality and Economic Growth: An Empirical Study, "Ecological Economics", 34, pp. 409 - 423, 2000.

Elliott, G., Rothenberg, T. J., Stock, J. H., Efficient Tests for an Autoregressive Root, "Econometrica", 64, pp. 813-836, 1996.

Enders, W., Chumrunsphonlert, K., Threshold Cointegration and Purchasing Power Parity in the Pacific Nations, “Applied Economics”, 36, pp. 889-896, 2004.

Enders, W., Granger, C. W. J., Unit-Root Tests and Asymmetric Adjustment with an Example Using the Term Structure of Interest Rates, "Journal of Business \& Economic Statistics", 16, pp. 304-311, 1998.

Enders, W., Siklos, P. L., Cointegration and Threshold Adjustment, "Journal of Business and Economic Statistics", 19, pp. 166-176, 2001.

Engle, F. R., Granger, C. W. J., Co-integration and Error Correction: Representation, Estimation, and Testing, "Econometrica", 55, pp. 251-276, 1987.

Esteve, V., Tamarit, C., Threshold Cointegration and Nonlinear Adjustment Between $\mathrm{CO}_{2}$ and Income: The Environmental Kuznets Curve in Spain, 1857-2007, "Energy Economics", 34, pp. 2148-2156, 2012.

Farhani, M., Shahbaz, M., Arouri, M. E. H., Panel Analysis of CO2 Emissions, GDP, Energy Consumption, Trade Openness and Urbanization for MENA Countries, MPRA Paper no. 49258, August 2013.

Fodha, M., Zaghdoud, O., Economic Growth and Pollutant Emissions in Tunisia: An Empirical Analysis of the Environmental Kuznets Curve, "Energy Policy", 38, pp. 1150$-1156,2010$.

Fosten, J., Morley, B., Taylor, T., Dynamic Misspecification in the Environmental Kuznets Curve: Evidence from $\mathrm{CO}_{2}$ and $\mathrm{SO}_{2}$ Emissions in the United Kingdom, "Ecological Economics", 76, pp. 25-33, 2012.

Friedl, B., Getzner, M., Determinants of CO2 Emissions in a Small Open Economy, "Ecological Economics", 45, pp. 133-148, 2003.

Gangadharan, L.,Valenzuela, M. R., Interrelationships between Income, Health and the Environment: Extending the Environmental Kuznets Curve Hypothesis, "Ecological Economics", 36, pp. 513-531, 2001.

Grossman, G. M., Krueger, A. B., Environmental Impacts of the North American Free Trade Agreement, NBER Working Paper No. 3914, November 1991.

Grossman, G. M., Krueger, A. B., Pollution and Growth: What Do We Know? [in:] Goldin, I., Winters, L., (eds.), The Economics of Sustainable Development. MIT Press, Cambridge, 1993.

Harbaugh, W., Levinson, A., Wilson, D. M., Reexamining the Empirical Evidence for an Environmental Kuznets Curve, "Review of Economics and Statistics", 84, pp. 541-551, 2002. 
He, J., Richard, P., Environmental Kuznets Curve for $\mathrm{CO}_{2}$ in Canada, "Ecological Economics", 69, pp. 1083-1093, 2010.

Heil, M. T., Selden, T. M., Panel Stationarity with Structural Breaks: Carbon Emissions and GDP, “Applied Economics Letters”, 6, pp. 223-225, 1999.

Hill, R. J., Magnani, E., An Exploration of the Conceptual and Empirical Basis of the Environmental Kuznets Curve, Australian Economic Papers No. 41, pp. 239-254, December 2002.

Holtz-Eakin, D., Selden, T. M., Stoking the Fires?:CO2 Emissions and Economic Growth, "Journal of Public Economics", 57, pp. 85-101, 1995.

Iwata, H., Okada, K., Samreth, S., Empirical Study on the Environmental Kuznets Curve for CO2 in France: The Role of Nuclear Energy, "Energy Policy”, 38, pp. 4057-4063, 2010.

Jalil, A., Mahmud, S. F., Environment Kuznets Curve for CO2 Emissions: A Cointegration Analysis, "Energy Policy", 37, pp. 5167-5172, 2009.

Jaunky, V. Ch., The CO2 Emissions-income Nexus: Evidence from Rich Countries, "Energy Policy", 39, pp. 1228-1240, 2011.

Kaika, D., Zervas, E., The Environmental Kuznets Curve (EKC) Theory. Part B: Critical Issues, "Energy Policy", 62, pp. 1403-1411, 2013.

Kaufmann, R. K., Davidsdottir, B., Garnham, S., Pauly, P., The Determinants of Atmospheric SO2 Concentrations: Reconsidering the Environmental Kuznets Curve, "Ecological Economics", 25, pp. 209-220, 1998.

Khanna, N., The Income Elasticity of Non-point Source Air Pollutants: Revisiting the Environmental Kuznets Curve, "Economics Letters", 77, pp. 387-392, 2002.

Kijima, M., Nishide, K., Ohyama, A., Economic Models for the Environmental Kuznets Curve: A Survey, "Journal of Economic Dynamics and Control", 34, pp. 1187-1201, 2010.

Komen, R., Gerking, S., Folmer, H., Income and Environmental R\&D: Empirical Evidence from OECD Countries, "Environment and Development Economics", 2, pp. 505-515, 1997.

Lieb, C. M., The Environmental Kuznets Curve - A Survey of the Empirical Evidence and of Possible Causes, University of Heidelberg - Department of Economics, Discussion Paper Series, No. 391, April 2003.

List, J. A., Gallet, C. A., The Environmental Kuznets Curve: Does One Size Fit All?, "Ecological Economics", 31, pp. 409-423, 1999.

Martin, P., Wheeler, D., Price, Policies and the International Diffusion of Clean Technology: The Case of Wood Pulp Production [in:] Low, P. (eds.), International Trade and the Environment, pp. 197-224.World Bank, Washington, 1992.

Mehrara, M., Musai, M., Nasibparast, S., The Causality between Savings and GDP in Iran, "International Journal of Advanced Research in Engineering and Applied Sciences", 1, pp. 43-55, 2012.

Narayan, P. K., Narayan, S., Carbon Dioxide Emissions and Economic Growth: Panel Data Evidence from Developing Countries, "Energy Policy”, 38, pp. 661-666, 2010.

Ozcan, B., The Nexus between Carbon Emissions, Energy Consumption and Economic Growth in Middle East Countries: A Panel Data Analysis, "Energy Policy", 62, pp. 1138$-1147,2013$. 
Panayotou, T., Demystifying the Environmental Kuznets Curve: Turning a Black Box into a Policy Tool, "Environment and Development Economics", 2, pp. 465-484, 1997.

Panayotou, T., Empirical Tests and Policy Analysis of Environmental Degradation at Different Stages of Economic Development, World Employment Programme Working Paper No. WP238, International Labor Office, Geneva, 1993.

Papież, M., CO2 Emissions, Energy Consumption and Economic Growth in the Visegrad Group Countries: A Panel Data Analysis, $31^{\text {st }}$ International Conference on Mathematical Methods in Economics, 2013.

Pasten, R., Figueroa, E., The Environmental Kuznets Curve: A Survey of the Theoretical Literature, "International Review of Environmental Resource Economics", 6, pp. 195$-224,2012$.

Petruccelli, J., Woolford, S. W., A Threshold AR(1) Model, "Journal of Applied Probability", 21, pp. 270-286, 1984.

Piłatowska, M., Włodarczyk, A., Zawada, M., The Environmental Kuznets Curve in PolandEvidence From Threshold Cointegration Analysis, "Dynamic Econometric Models", 14, pp. 51-70, 2014.

Piłatowska, M., Włodarczyk, A., Zawada, M., CO2 Emissions, Energy Consumption and Economic Growth in the EU Countries: Evidence from Threshold Cointegration Analysis, IEEE Conference Proceedings on the European Energy Market, EEE Catalog Number CFP-1552D-USB; ISBN 978-1-4673-6691-5; DOI: 10.1109/EEM.2015.7216646.

Richmond, A. K., Kaufman, R. K., Is There a Turning Point in the Relationship between Income and Energy Use and/or Carbon Emissions?, "Ecological Economics", 56, pp. 176-189, 2006.

Roca, J., Do Individual Preferences Explain Environmental Kuznets Curve?, "Ecological Economics", 45, pp. 3-10, 2003.

Saboori, B., Sulaiman, J., Mohd, S., Economic Growth and CO2 Emissions in Malaysia: A Cointegration Analysis of the Environmental Kuznets Curve, "Energy Policy", 51, pp. 184-191, 2012.

Sax, Ch., Steiner, P., Temporal Disaggregation of Time Series, “The R Journal”, 5, pp. 80-97, 2013.

Shafik, N., Bandyopadhyay, S., Economic Growth and Environmental Quality: Time Series and Cross Section Evidence, World Development Report Working Paper WPS 904, The World Bank, Washington, DC, 1992.

Shafik, N., Economic Development and Environmental Quality: An Econometric Analysis, "Oxford Economic Papers", 46, pp. 757-773, 1994.

Shahbaz, M., Mutascu, M., Azim, P., Environmental Kuznets Curve in Romania and the Role of Energy Consumption, "Renewable and Sustainable Energy Reviews", 18, pp. 165-173, 2013.

Soytas, U., Sari, R., Energy Consumption, Economic Growth and Carbon Emission: Challenges Faced by an EU Candidate Member, "Ecological Economics", 68, pp. 1667$-1675,2009$.

Soytas, U., Sari, R., Ewing, B. T., Energy Consumption, Income and Carbon Emissions in the United Stated, "Ecological Economics”, 62, pp. 482-489, 2007. 
Stern, D. I., The Rise and Fall of the Environmental Kuznets Curve, "World Development", 32, pp. 1419-1439, 2004.

Stern, N., The Economics of Climate Change : the Stern Review. HM Treasury, Cabinet Office, London, 2006.

Suri, V., Chapman, D., Economic Growth, Trade and Energy: Implications for the Environmental Kuznets Curve, "Ecological Economics", 25, pp. 195-208, 1998.

Tang, Ch. F., Tan, B. W., The Impact of Energy Consumption, Income and Foreign Direct Investment on Carbon Dioxide Emissions in Vietnam, "Energy", 79, pp. 447-454, 2015.

Unleashing Prosperity: Productivity Growth in Eastern Europe and the Former Soviet Union. The World Bank, Washington, D.C., 2008.

Wagner, M., The Carbon Kuznets Curve: A Cloudy Picture Emitted by Bad Econometrics?, "Energy and Resource Economics", 30, pp. 388-408, 2008.

Wane, K. M., Gilbert, S., Dibooglu, S., Critical Values of the Empirical F-Distribution for Threshold Autoregressive and Momentum Threshold Autoregressive Models, Discussion Papers for the Department of Economics, Southern Illinois University at Carbondale, 2004.

Wang, K-M., Modelling the Nonlinear Relationship between CO2 Emissions from Oil and Economic Growth, "Economic Modelling", 29, pp. 1537-1547, 2012.

Wyckoff, A. W., Roop, J. M., The Embodiment of Carbon in Imports of Manufactured Products: Implications for International Agreements on Greenhouse Gas Emissions, "Energy Policy", 22, pp.187-194, 1994.

Yau, H.-Y., Nieh, C.-C., Testing for Cointegration with Threshold Effect between Stock Prices and Exchange Rates in Japan and Taiwan, "Japan and World Economy", 21, pp. 292-300, 2009.

Received: January 2016, revised: May 2017 


\section{APPENDIX}

Table A1

The results of the ADF-GLS unit root test for the CEE countries

\begin{tabular}{|c|c|c|c|c|c|c|}
\hline \multirow{2}{*}{ Variables } & \multicolumn{3}{|c|}{ Levels } & \multicolumn{3}{|c|}{ Differences } \\
\hline & $\mathbf{n}$ & c & $\mathbf{c}+\mathbf{t}$ & $\mathbf{n}$ & c & $c+t$ \\
\hline \multirow[t]{2}{*}{1} & 2 & 3 & 4 & 5 & 6 & 7 \\
\hline & \multicolumn{6}{|c|}{ Bulgaria } \\
\hline $\mathrm{CO}_{\mathrm{t}}$ & -1.038 & $-1.856^{*}$ & -1.972 & $-5.623^{* * *}$ & $-5.367^{* * *}$ & $-5.436^{* * *}$ \\
\hline $\mathrm{GDP}_{\mathrm{t}}$ & 1.177 & 0.963 & -1.209 & $-3.878^{* * *}$ & $-5.141^{* * *}$ & $-5.1334^{* * *}$ \\
\hline $\mathrm{GDP}_{\mathrm{t}}^{2}$ & 1.121 & 0.953 & -1.227 & $-3.828^{* * *}$ & $-5.066^{* * *}$ & $-5.065^{* * *}$ \\
\hline \multirow[t]{2}{*}{$\mathrm{E}_{\mathrm{t}}$} & -0.516 & -1.836 & -2.018 & $-5.604^{* * *}$ & $-3.996^{* * *}$ & $-4.803^{* * *}$ \\
\hline & \multicolumn{6}{|c|}{ Czech Republic } \\
\hline $\mathrm{CO}_{\mathrm{t}}$ & -0.853 & -0.421 & -1.565 & $-5.462^{* * *}$ & $-4.500^{* * *}$ & $-5.485^{* * *}$ \\
\hline $\mathrm{GDP}_{t}$ & 0.567 & 0.600 & -1.353 & $-3.435^{* * *}$ & $-3.329^{* * *}$ & $-4.066^{* * *}$ \\
\hline $\mathrm{GDP}_{\mathrm{t}}{ }^{2}$ & 0.544 & 0.596 & -1.366 & $-3.453^{* * *}$ & $-3.411^{* * *}$ & $-4.095^{* * *}$ \\
\hline \multirow[t]{2}{*}{$\mathrm{E}_{\mathrm{t}}$} & -0.024 & -1.421 & -1.525 & $-5.813^{* * *}$ & $-5.791^{* * *}$ & $-5.896^{* * *}$ \\
\hline & \multicolumn{6}{|c|}{ Estonia } \\
\hline $\mathrm{CO}_{\mathrm{t}}$ & -0.281 & $-2.437^{* *}$ & -2.610 & $-6.258^{* * *}$ & $-5.573^{* * *}$ & $-6.192^{* * *}$ \\
\hline $\mathrm{GDP}_{\mathrm{t}}$ & 0.599 & 0.277 & -1.239 & $-3.276^{* * *}$ & $-3.953^{* * *}$ & $-4.446^{* * *}$ \\
\hline $\mathrm{GDP}_{\mathrm{t}}{ }^{2}$ & 0.519 & 0.275 & -1.313 & $-3.329^{* * *}$ & $-4.022^{* * *}$ & $-4.416^{* * *}$ \\
\hline \multirow[t]{2}{*}{$\mathrm{E}_{\mathrm{t}}$} & 0.344 & -0.826 & -2.436 & $-6.084^{* * *}$ & $-5.877^{* * *}$ & $-6.158^{* * *}$ \\
\hline & \multicolumn{6}{|c|}{ Hungary } \\
\hline $\mathrm{CO}_{\mathrm{t}}$ & -1.138 & 1.323 & -0.529 & $-5.478^{* * *}$ & $-5.418^{* * *}$ & $-6.698^{* * *}$ \\
\hline $\mathrm{GDP}_{\mathrm{t}}$ & 0.911 & 0.175 & -0.576 & $-3.323^{* * *}$ & $-4.078^{* * *}$ & $-4.536^{* * *}$ \\
\hline $\mathrm{GDP}_{\mathrm{t}}{ }^{2}$ & 0.869 & 0.183 & -0.588 & $-3.371^{* * *}$ & $-4.114^{* * *}$ & $-4.556^{* * *}$ \\
\hline \multirow[t]{2}{*}{$\mathrm{E}_{\mathrm{t}}$} & -0.604 & -0.591 & -0.713 & $-6.569^{* * *}$ & $-5.256^{* * *}$ & $-6.926^{* * *}$ \\
\hline & \multicolumn{6}{|c|}{ Latvia } \\
\hline $\mathrm{CO}_{\mathrm{t}}$ & -1.124 & 1.010 & -1.791 & $-7.108^{* * *}$ & $-6.408 * * *$ & $-7.533^{* * *}$ \\
\hline $\mathrm{GDP}_{\mathrm{t}}$ & 1.091 & 0.939 & -1.559 & $-3.165^{* * *}$ & $-4.544 * * *$ & $-4.674^{* * *}$ \\
\hline $\mathrm{GDP}_{\mathrm{t}}^{2}$ & 1.062 & 0.964 & -1.577 & $-3.221^{* * *}$ & $-4.634 * * *$ & $-4.717^{* * *}$ \\
\hline \multirow[t]{2}{*}{$\mathrm{E}_{\mathrm{t}}$} & -0.317 & -1.040 & -1.576 & $-7.606 * * *$ & $-7.560 * * *$ & $-7.839^{* * *}$ \\
\hline & \multicolumn{6}{|c|}{ Lithuania } \\
\hline $\mathrm{CO}_{\mathrm{t}}$ & $-3.20^{* * *}$ & -1.22 & -1.70 & $-5.67^{* * * *}$ & $-5.42^{* * *}$ & $-5.80^{* * *}$ \\
\hline $\mathrm{GDP}_{\mathrm{t}}$ & 0.99 & 0.76 & -1.49 & $-3.54^{* * *}$ & $-4.76^{* * *}$ & $-4.91^{* * *}$ \\
\hline $\mathrm{GDP}_{\mathrm{t}}{ }^{2}$ & 0.91 & 0.77 & -1.58 & $:-3.62^{* * *}$ & $-4.82^{* * *}$ & $-4.91^{* * *}$ \\
\hline \multirow[t]{2}{*}{$\mathrm{E}_{\mathrm{t}}$} & -0.42 & $-1.76^{*}$ & -1.80 & $-5.16^{* * *}$ & $-3.97^{* * *}$ & $-4.91^{* * *}$ \\
\hline & \multicolumn{6}{|c|}{ Poland } \\
\hline $\mathrm{CO}_{\mathrm{t}}$ & -0.69 & -1.00 & -1.58 & $-5.60^{* * *}$ & $-5.22^{* * *}$ & $-5.47^{* * *}$ \\
\hline $\mathrm{GDP}_{\mathrm{t}}$ & 0.69 & 0.37 & -1.47 & $-1.78^{*}$ & $-2.94^{* * *}$ & $-4.00^{* * *}$ \\
\hline $\mathrm{GDP}_{\mathrm{t}}{ }^{2}$ & 0.61 & 0.38 & -1.62 & $-1.78^{*}$ & $-3.18^{* * *}$ & $-4.02^{* * *}$ \\
\hline $\mathrm{E}_{\mathrm{t}}$ & -0.43 & -1.41 & -1.43 & $-5.75^{* * *}$ & $-4.11^{* * *}$ & $-4.91^{* * *}$ \\
\hline
\end{tabular}


Table A1, cont.

\begin{tabular}{l|c|c|c|c|c|c}
\hline \multicolumn{1}{c|}{1} & 2 & 3 & 4 & 5 & 6 & 7 \\
\hline & \multicolumn{6}{|c|}{ Romania } \\
\hline $\mathrm{CO}_{\mathrm{t}}$ & $-3.56^{* * *}$ & -1.05 & -2.05 & $-4.32^{* * *}$ & $-3.79^{* * *}$ & $-4.16^{* * *}$ \\
\hline $\mathrm{GDP}_{\mathrm{t}}$ & 0.53 & 0.50 & -1.48 & $-3.65^{* * *}$ & $-3.71^{* * *}$ & $-3.94^{* * *}$ \\
\hline $\mathrm{GDP}_{\mathrm{t}}{ }^{2}$ & 0.53 & 0.52 & -1.46 & $-3.70^{* * *}$ & $-3.81^{* * *}$ & $-4.02^{* * *}$ \\
\hline $\mathrm{E}_{\mathrm{t}}$ & -0.75 & -1.30 & -1.79 & $-4.72^{* * *}$ & $-3.38^{* * *}$ & $-4.11^{* * *}$ \\
\hline \multicolumn{7}{|c}{ Slovakia } \\
\hline $\mathrm{CO}_{\mathrm{t}}$ & -1.12 & 1.01 & -1.79 & $-7.11^{* * *}$ & $-6.41^{* * *}$ & $-7.53^{* * *}$ \\
\hline $\mathrm{GDP}_{\mathrm{t}}$ & 1.09 & 0.94 & -1.56 & $-3.16^{* * *}$ & $-4.54^{* * *}$ & $-4.67^{* * *}$ \\
\hline $\mathrm{GDP}_{\mathrm{t}}{ }^{2}$ & 1.06 & 0.96 & -1.58 & $-3.22^{* * *}$ & $-4.63^{* * *}$ & $-4.72^{* * *}$ \\
\hline $\mathrm{E}_{\mathrm{t}}$ & -0.32 & -1.04 & -1.58 & $-7.61^{* * *}$ & $-7.56^{* * *}$ & $-7.84^{* * *}$ \\
\hline $\mathrm{CO}_{\mathrm{t}}$ & -0.55 & -1.19 & -1.44 & $-6.04^{* * *}$ & $-4.27^{* * *}$ & $-5.85^{* * *}$ \\
\hline $\mathrm{GDP}_{\mathrm{t}}$ & 0.62 & 0.22 & -0.54 & $-3.77^{* * *}$ & $-4.19^{* * *}$ & $-5.48^{* * *}$ \\
\hline $\mathrm{GDP}_{\mathrm{t}}{ }^{2}$ & 0.58 & 0.21 & -0.57 & $-3.83^{* * *}$ & $-4.27^{* * *}$ & $-5.46^{* * *}$ \\
\hline $\mathrm{E}_{\mathrm{t}}$ & -0.003 & -0.60 & -1.68 & $-6.61^{* * *}$ & $-4.97^{* * *}$ & $-6.51^{* * *}$ \\
\hline
\end{tabular}

Note: $\left({ }^{* * *}\right),\left({ }^{* *}\right),\left({ }^{*}\right)$ in ADF-GLS tests indicate the rejection of the null hypothesis that series has a unit root at $1 \%, 5 \%$ and $10 \%$ levels of significance. The optimum lag lengths were determined using BIC in ADF-GLS tests.

Source: authors' calculations. 